\begin{tabular}{c|c|}
\hline \\
Université \\
de Liège
\end{tabular}

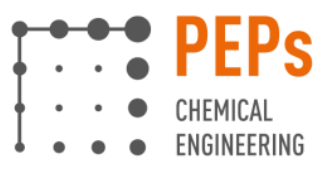

\title{
Separation and Purification
}

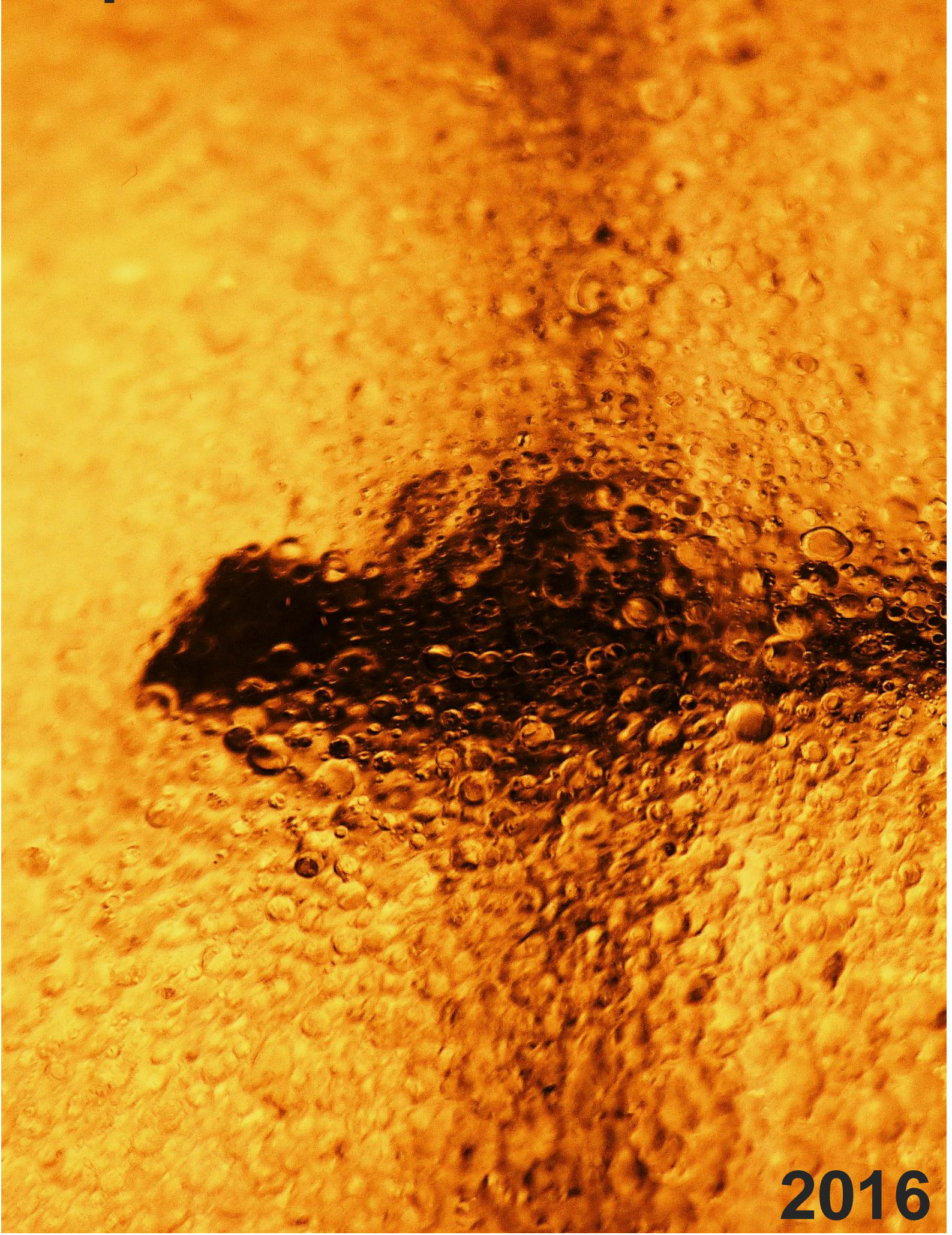




\section{Content}

Dear Reader

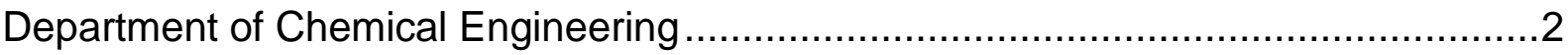

David Leleu

Modeling of Polydisperse Sedimentation Using Alginate Gel Beads

Marjan Mohammadi Sarab Badieh, Javad Saien

Salt effect on the equilibrium system of water + acetone + HMIMPF6 ionic liquid.......6

Maria Chiara Quaresima

Extraction-Column Design for Highly Viscous Systems.

Andreas Pfennig

Last Three Ph.D. Theses Defenses at TU Graz

Andreas Pfennig

Advantages of Centrifugal Extraction

Evaluation of Exergy Applied to Alternative Biobased Processes

Cascaded Option Trees used for Systematic Selection of Reactive Extractants

Andreas Pfennig

Teaching and Research on YouTube

Andreas Pfennig

Lecturing in Bangkok and Oman

Andreas Pfennig

The Schnapps Project

Dissertations, Publications, and Presentations

title photo by:

David Leleu, Thierry Salmon

showing a closeup of the standardized settling cell in operation 


\section{Dear Reader}

Meanwhile the second year has passed since I moved to Liège in Belgium, where the group is slowly growing and the infrastructure is developing so that it can be used for our research. For example, the single-drop cells are operational again, with the help from former coworkers from Aachen and Graz, namely Andreas Bednarz, Eva Kalvoda, and Markus Lückge, for which we are quite thankful. Currently these cells are also used by Ms. Marjan Mohammadi Sarab Badieh, who is a guest from the Bu-Ali Sina University in Iran, supervised by professor Dr. Javad Saien.

After having moved to Liège, I am frequently asked, if the research focus of my group has changed. It is still solvent extraction, phase separation, and exergetic evaluations of processes, together with the corresponding fundamentals especially in mass transfer and thermodynamics. In principle, also other thermal separation processes can be treated as well, as for example distillation of aqueous systems in the past. We are applying our methods especially for the development of biobased processes, phosphorus recovery from sewage sludge, and urban mining - to mention just some topics.

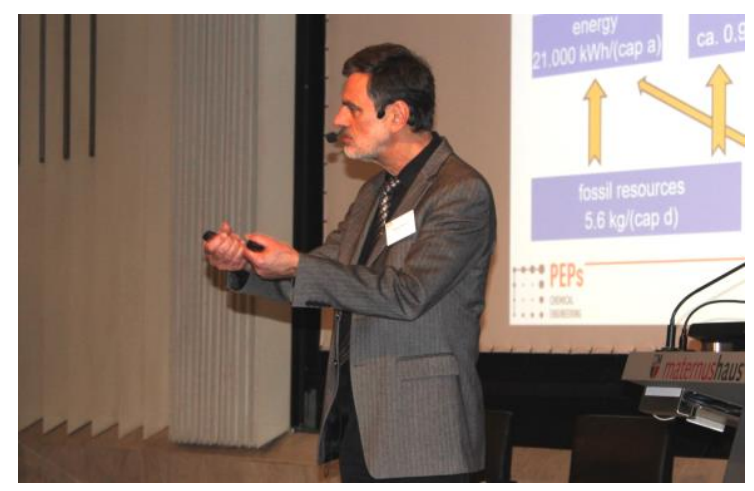

Fig. 1: Invited to Bioeconomy Science Center Symposium, 21.11. in Cologne (photo: Forschungszentrum Jülich)

The second question usually asked relates to the language, in which I am teaching: English. That is part of my contract, thus this contribution to the internationalization of the University of Liège was explicitly desired. On the other hand and to calm those, with whom I am di- rectly interacting at the university, I am very well aware that I need to learn French, because Liège is - apparently - located in the French-speaking part of Belgium, in Wallonia. The progress is - also apparently - unfortunately a question of available time.

Our campus is located in Liège, but at quite some distance from the city center. The buildings of the campus are integrated into forests, which are utilized as an outdoor museum (Le Musée en Plein Air), where every some $100 \mathrm{~m}$ along the trails some exhibit can be observed. The interested reader can find a more detailed description at http://www.museepla.ulg.ac.be/. An example found near our offices is shown in Fig. 2. At the same time the area is a nature reserve.

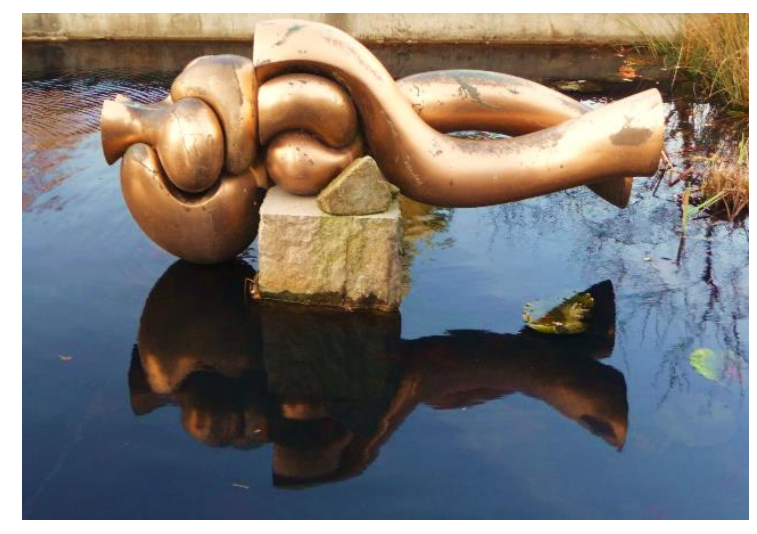

Fig. 2: Art at the campus Sart-Tilman

In this inspiring environment, which invites to extended contemplations, we are thus trying to understand the behavior on the small scales of chemical-engineering processes as basis for large-scale equipment design. Some aspects of our walk between the scales are presented on the following pages, which can of course only show a glimpse of the details regarded. In parallel in a variety of direct interactions with industry, we have transferred our knowledge into the industrial realm, e.g. with dedicated industry workshops. Finally, in this report also some non-research topics are covered. Enjoy reading!

Andreas Pfennig 


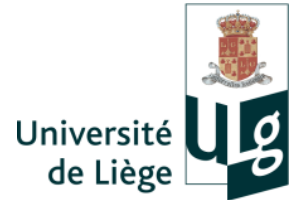

\section{Department of Chemical Engineering}

Our research group is embedded in the PEPs group (Products, Environment, and Processes), which is one of the three groups in the Department of Chemical Engineering, which is part of the Faculty of Applied Sciences. The research at the Department of Chemical Engineering is covering the design and integration of unit operations as well as the corresponding fundamentals like mass transfer and reaction kinetics, but also focusses on a variety of specific product-oriented themes like environment, batteries and fuel cells. Research is organized along three main axes:

- Cryotechnology (Cryo): The CRYO Group is specialized on solving specific problems for components or motors for the European 'Ariane' cryogenic equipment. Test benches are used, with the major characteristic of complete instrumentation and very fast and flexible data acquisition. One of these benches is used to investigate dynamic sealing relevant for the front-powered vinci, the last stage of the future 'Ariane 6' engine.

- Nanomaterials, Catalysis, Electrochemistry (NCE): The NCE focusses on development of nanostructured materials for various applications such as catalysis, electrochemistry and functionalized coating. The specific strength of NCE research lies in its transversality, integrating matters of material science and chemical engineering. Major research topics are the

- synthesis, formatting and pilot scale production of nanostructured materials

- characterization and development of tools for the characterization of nanostructured materials

- application of nanostructured materials in catalysis, electrochemistry and effluent treatment

- Products, Environment, and Processes (PEPs): The PEPs group deals with reactor technology and separation processes as well as the required fundamentals like fluid dynamics, heat and mass transfer, and reaction kinetics. The individual unit opera- tions are integrated into processes aiming at optimal products and process performance. Areas of application are biobased products, carbon capture and conversion, as well as environmental issues like wastewater treatment.

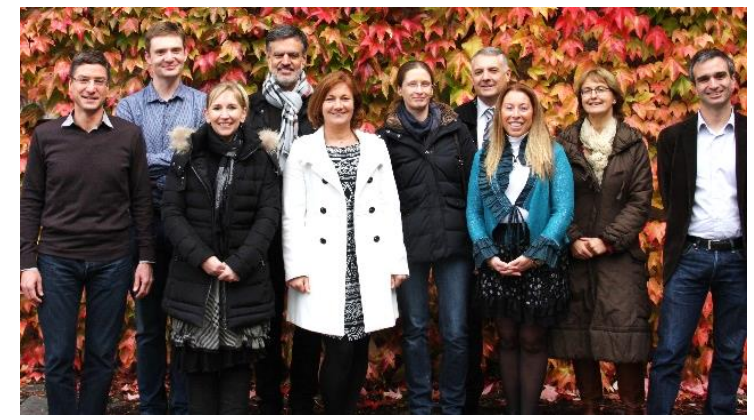

Fig. 1: Permanent members of the Department of Chemical Engineering, from left:

Benoît Heinrichs, Grégoire Léonard, Angélique Léonard, Andreas Pfennig, Dominique Toye, Nathalie Job, Jean-Luc Bozet, Stéphanie Lambert, Marie-Noëlle Dumont, Cédric Gommes

In the PEPs group, we are active in the fields of (bio-) chemical reaction engineering, thermal and mechanical unit operations, process simulation, low carbon energy systems and sustainable development. This includes the corresponding fundamentals, especially mass and energy transfers, and multi-phase fluid dynamics. A strength of our approach is to link the different scales in time and space:

- starting from microscopic and even molecular level

- having a strong focus on the equipment level in experiment as well as modelling

- reaching up to the simulation of entire processes

- and evaluating the favored large-scale deployment pathway.

This allows us to reliably describe and optimize equipment performance based on physically sound modelling, which even includes extrapolation beyond the region of experiments. These 


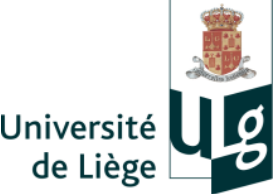

tools permit a knowledge-based optimization of equipment design and operation parameters, as a basis for safe, sustainable and profitable scale-up of the processes. Indeed, the simulation of entire processes together with Life Cycle Assessment (LCA) as eco-design support guide the optimization on the process level, where economic as well as environmental parameters are included in the evaluation.

Experimental infrastructure is available for model development and validation, covering a wide range of applications, e.g.

- to study hydrodynamics in a various equipment with $x$-ray tomography on large scale and trajectography of drops and particles,

- to follow the microstructure of materials and systems during their processing especially in a product-oriented engineering approach with (micro-) tomography,

- lab-scale measuring devices for characterization of behavior of drops and dispersions as well as pilot-plant scale equipment for various unit operations like drying and distillation.

In addition, adequate chemical analysis equipment is used to determine gas and liquid phase compositions, including various chromatography and X-ray devices.

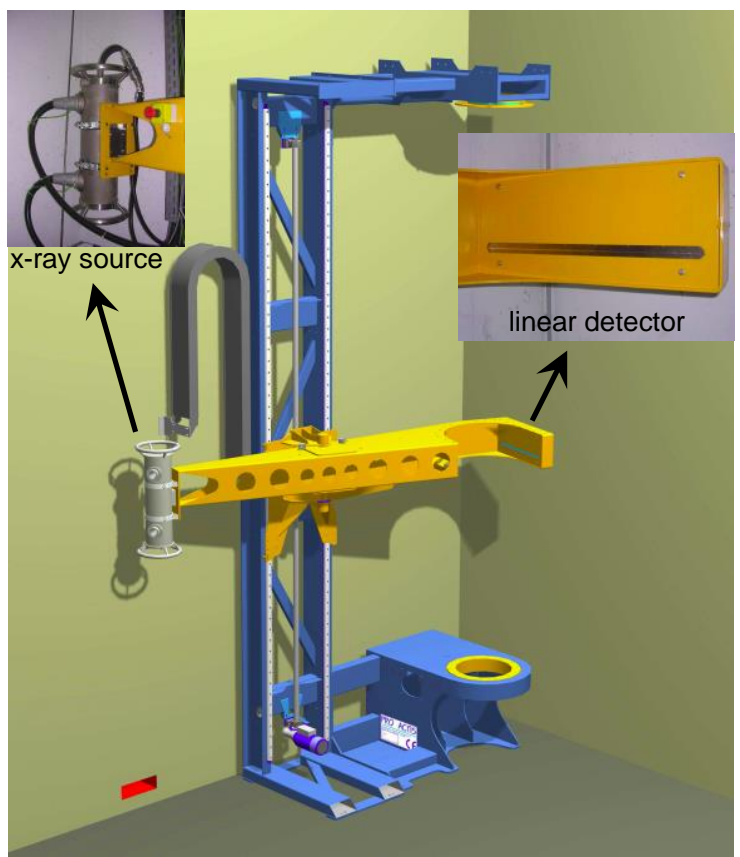

Fig. 2: X-ray tomograph for equipment with up to $45 \mathrm{~cm}$ diameter and $4 \mathrm{~m}$ length, and a resolution of $0.5 \mathrm{~mm}$

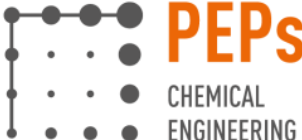

The future perspective of our research - besides further development of our fundamental methods - is to get chemical-engineering design tools prepared for the future. Thus our current research topics aim at allowing safe design of sustainable chemical and biobased processes, where process-specific material and energy transformations imply properties changes in the systems like e.g. increased viscosity, posing challenges to the chemical engineer. Similarly the recycle of used material like recovery of phosphorus from sewage sludge or the separation of rare earth elements in urban mining create new and challenging engineering tasks. In particular, main and alternative routes have to be evaluated and compared for sustainability and this can be done with the methods we design.

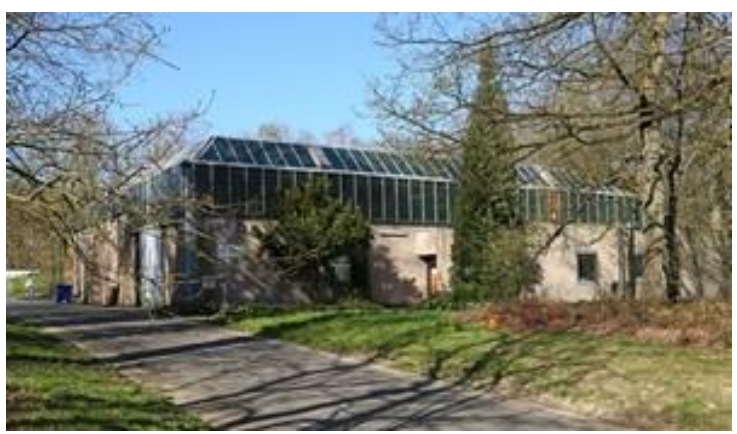

Fig. 2: Technical hall for larger equipment

The majority of our methods and applications is developed in cooperation or at least in close contact with industry, including essentially all major chemical companies and a variety of local and European SMEs.

The University of Liège also has strong activities in the areas of biotechnology, microbiology, and biological sciences, including agronomy, which is located at the Gembloux campus and organized in the faculty Agro-Bio Tech. The Department of Chemical Engineering has established close links to Agro-Bio Tech.

Thus at the University of Liège we combine all expertise required to design chemical-engineering processes and equipment in detail and as a whole, including environmental issues and overall process optimization.

For further questions and comments, please contact:

Andreas Pfennig

phone: +32 (0) 4 366-3521

andreas.pfennig@ulg.ac.be 


\section{\begin{tabular}{|l|l|}
\hline & \\
\hline
\end{tabular}}

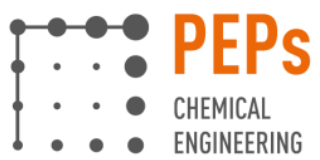

\section{Modeling of Polydisperse Sedimentation Using Alginate Gel Beads}

\section{Motivation}

Separation of liquid-liquid dispersions with multiple phases involves different interactions between the different dispersed species present in the system, which makes it difficult to predict e.g. the separation behavior. Nevertheless such systems are relevant in chemical engineering e.g. for systems involving drops, gas bubbles and simultaneously solid particles like in a fermentation broth. Models for describing the sedimentation behavior as a basis for settler design are available in principle, but have not been systematically validated for variation in size-distribution and e.g. density differences between the various species in the system. Thus, to design technical separation equipment, the separation process has to be better understood, which requires the study of the sedimentation as a first step.
\end{abstract}

David Leleu

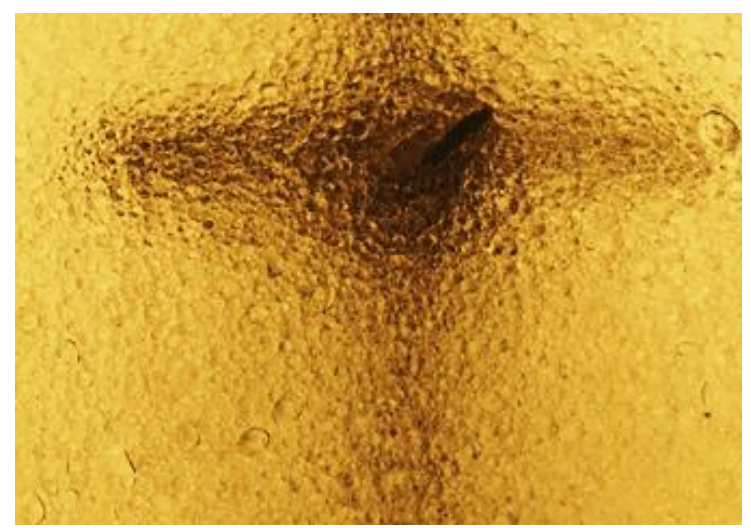

Fig. 1: Polydisperse drop-size distribution in the Henschke settling cell

This project is focused on the interactions, which occur between each species during the sedimentation like the effect of polydispersity on sedimentation, as shown on Fig. 1 or the effect of descending particles when they meet ascending drops. However, a proper study of the sedimentation with fluid phases is difficult due to other phenomena occurring simultaneously, like coalescence. To overcome this issue, the use of gel beads is proposed, which due to their solid interface cannot coalesce. In addition, it is easy to define their parameters, which are the density, the hardness and the size distribution. Besides, they can also be preserved during an extended period of time, experiments can thus be reproduced many times with identical beads.

\section{First Results}

The first part of the project focusses on production and characterization of alginate gel beads. Their production should be simple and reproducible while allowing easy and flexible modification of their properties.

The developed process allows changing the color by adding pigments and the density by adding e.g. copper powder or oil in the alginate solution. The solution is injected through a needle to produce alginate drops. The drops are then driven by an airflow surrounding the needle. Drops then enter into a calcium-chloride solution leading to gelation. The size distribution can be defined by changing the air flow rate and the needle diameter.

Calibration experiments have been be performed testing the different experimental parameters. These tests are useful to easily define the bead parameters during their production. An illustration of alginate copper beads is shown on Fig. 2.

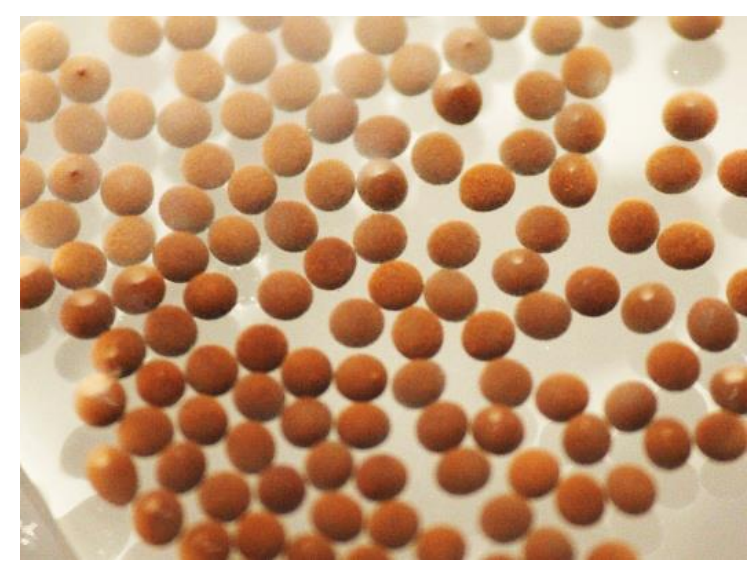

Fig. 2: Copper-enriched beads, $2 \mathrm{~mm}$ diameter 


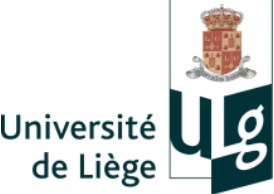

In a next step, the gel beads need to be characterized in term of density and size distribution. The alginate-gel beads sediment very slowly, which is an advantage regarding the sedimentation studies, however in order to validate mathematical models, the characterization needs to be as precise as possible due to the almost floating characteristics.

A picture analysis, running on Matlab, is used to evaluate the particle size distribution. This tool allows a precision of $0.2 \mathrm{~mm}$ on the beads diameter and can analyze hundreds of particles in one picture. The size distribution is so narrow that the assumption of monodisperse drops is justified.

The density is measured by transferring individual beads into a liquid of a known density, evaluated with a precision densimeter (DSA 5000M, Anton Paar, Graz, Austria), which allows precision of $10^{-5} \mathrm{~g} / \mathrm{cm}^{3}$. The evaluation has to be performed quickly, because otherwise the properties of the beads change due to the permeability of gel structure, which allows mass transfer to occur.

In a next step, a mathematical model, which describes sedimentation of polydisperse drops, is to be validated, modified, or derived. Different models exist and work perfectly for a swarm of monodispersed particles, some of which are presented in Fig. 3 for a particular spherical particle. A first step consists to choose and validate the optimal model for monodispersed beads. For this purpose, a sensitivity analysis has been performed to choose the optimal bead characteristics in terms of density and size, in order to differentiate between the models for sedimentation velocity. The experimental validation is to be performed in the Henschke settling cell.

The Henschke settling cell was developed some time ago as a standard equipment used to characterize settling in liquid-liquid dispersions (Henschke et al., 2002, Schlieper et al., 2004). The cell consists of a double-walled glass vessel of roughly one liter volume. The dispersion is created with two counter-rotating shafts with attached stirrers to avoid turbulence when the engine is stopped. A gearbox links the shafts to the engine. The latter allows a perfect control of the stirrer speed.

In the future, a model accounting for the interaction between polydisperse particles needs to be validated. In a system where ascending and descending particles are present, each type of particles can be regarded as a polydisperse swarm, where the sedimentation will be hindered by particles moving in opposite direction. These interactions should be described by the seeked mathematical model.

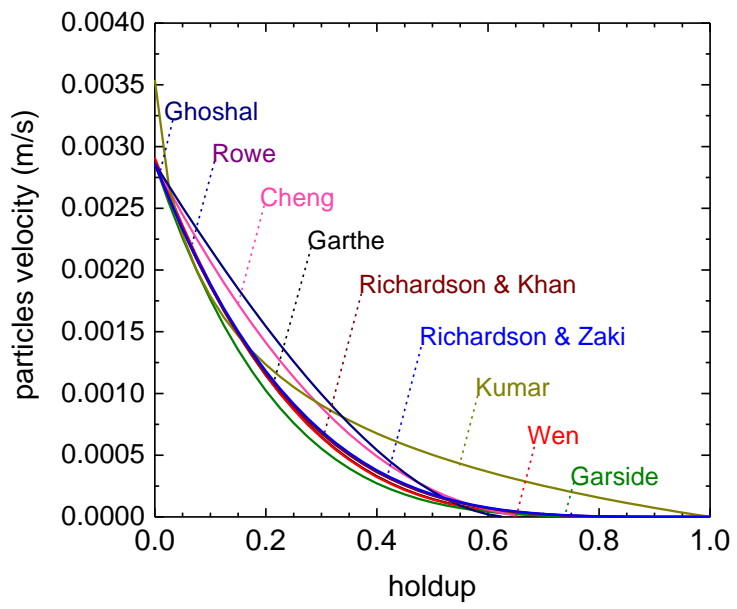

Fig. 3: Monodispersed swarm models.

The developed model will then be validated by performing experiments in the settling cell. During an experiment, different kind of beads will be mixed in the vessel. As each kind of particles is essentially monodisperse, the tracking of the sedimentation front will be sufficient to evaluate the sedimentation velocity. In order to differentiate and analyze each class of beads individually, they are colored with pigments, preferably in black and white to improve the contrast. Depending on the lighting, one kind of beads can be focused on. A numerical tool based on Matlab has already been developed for the evaluation of the velocities of each front recorded on video.

\section{References}

Henschke, M., Schlieper, L.H., Pfennig, A., 2002: Determination of a coalescence parameter from batch-settling experiments. Chem. Eng. J. 85(2-3), 369-378.

Schlieper, L., Chatterjee, M., Henschke, M., Pfennig, A., 2004: Liquid-Liquid Phase Separation in Gravity Settler with Inclined Plates. AlChE J., 50(4), 802-811.

For further questions and comments, please contact:

David Leleu

phone: +32 (0) 4 366-3559

dleleu@ulg.ac.be 


\title{
$\underset{\substack{\text { Univesite } \\ \text { delitige }}}{\text { UI }}$
}

\section{Salt effect on the equilibrium system of water + acetone + $\mathrm{HMIMPF}_{6}$ ionic liquid}

\author{
Marjan Mohammadi Sarab Badieh, Javad Saien
}

\section{Motivation}

Liquid-liquid extraction has frequently been regarded as a desired process in many cases for separation and purification. Traditional extraction methods often use organic solvents in contact with aqueous phases. Environmentally safe technologies may reject such anachronistic processes due to their toxicity, flammability and volatile organic compounds (VOCs).

To solve these problems, liquid-liquid extraction has been recently introduced with the aid of specific green solvents such as room temperature ionic liquids (RTILs or simply ILs). ILs exhibit excellent properties such as negligible vapor pressure, non-flammability and tunable physiochemical properties; thus they have been known as "designer solvents" for particular applications. Their negligible vapor pressure permits the extracted products to be separated from ILs by conventional low-pressure distillation. Nonvolatile or thermal sensitive products could also be recovered from ILs by supercritical carbon dioxide

One major requirement in evaluating the performance of liquid-liquid extraction process is the systems equilibrium data. Here, liquidliquid equilibrium (LLE) of ternary components, containing ILs and organic molecules have been studied. These mixtures are comprised of one IL and two organic molecules that have close boiling points or form an azeotrope, such as IL + aromatic + aliphatic, IL + ether + alcohol, IL + alkane + alkene, and so on. The work has been developed further for the mixture of hydrophobic ILs in contact with aqueous solutions containing organic solutes such as alcohols.

The aim of this work was utilizing an IL, formed by 1-hexyl-3-methylimidazolium $\left(\mathrm{HMIM}^{+}\right)$cation and hexafluorophosphate $\left(\mathrm{PF}_{6}{ }^{-}\right)$anion introduced as "HMIMPF 6 " (see Fig. 1), in a liquid-liquid extraction process in aqueous solutions for the first time. The liquid-liquid equilib- rium (LLE) of the ternary system water + acetone + $\mathrm{HMIMPF}_{6}$ and the quaternary system water + acetone + $\mathrm{HMIMPF}_{6}+$ salt are studied here.



Fig. 1: The chemical structure of $\mathrm{HMIMPF}_{6}$

\section{First Results}

First, we studied the LLE of the system water + acetone + $\mathrm{HMIMPF}_{6}$ ionic liquid. The high capability of this IL, as a green solvent, for extraction of acetone from aqueous solutions was explored. Acetone and water components have been involved in one standard chemical test system, recommended by the European Federation of Chemical Engineers (EFCE) for liquid-liquid extraction studies.

Considering the inevitable presence of electrolytes and their important role in altering the LLE of pure chemical systems, the influence of two conventional water-present salts, with monovalent $(\mathrm{NaCl})$ and divalent $\left(\mathrm{Na}_{2} \mathrm{SO}_{4}\right)$ anions from the Hofmeister series, on the mentioned ternary system was investigated. The data for the salt-free system show that acetone is more soluble in the IL phase than in the aqueous phase, which may be due to hydrogen bonding between acetone and the IL. Indeed, because of the salting-out effect, the solubility of acetone in the aqueous phase decreases in the presence of salts and, therefore, its extraction by the IL is significantly improved. Results show that the salting-out effect was significant. The stronger anion activity and the lack of anion exchange with the used ionic 


\section{\begin{tabular}{c|c|c|c|c|}
\hline & \\
Université \\
de Liège
\end{tabular}}

liquid can be the reasons for the stronger effect of the $\mathrm{Na}_{2} \mathrm{SO}_{4}$ salt than the $\mathrm{NaCl}$ salt.

Figs. 2 and 3 indicate that a greater binary region (shaded area) is achieved by the salt addition due to the decreased tendency of water-IL miscibility. Of course, solubility of the IL in water is to some extent less than that of water in the IL. Surely, the effect of salts on the solubility of ILs follows the charge-density series (the Hofmeister series) because a higher charge density results in stronger chargeneutralizing ion pairs.



Fig. 2: Binary regions, tie-line $(\Delta, \bullet$ and -) and solubility data $(\Delta, \circ$ and $\square)$ for salt-free, 0.05 and 0.10 mass fractions of $\mathrm{NaCl}$.

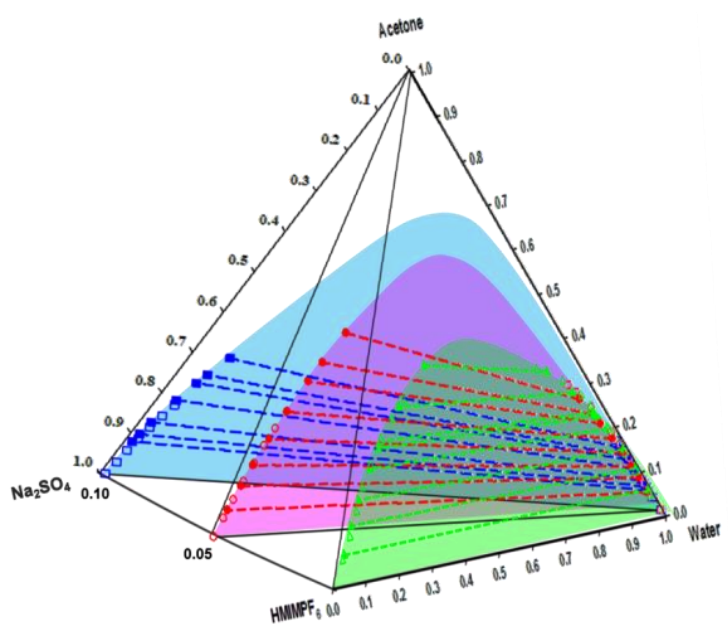

Fig. 3: Binary regions, tie-line $(\boldsymbol{\Delta}, \bullet$ and $\boldsymbol{\square})$ and solubility data $(\Delta, \circ$ and $\square)$ for saltfree, 0.05 and 0.10 mass fractions of $\mathrm{Na}_{2} \mathrm{SO}_{4}$.

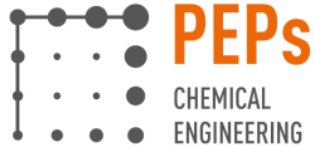

The consistency of the experimental data were examined with the improved Eisen-Joffe equation. For modeling the well known NRTL and UNIQUAC thermodynamic models were employed and the interaction parameters were determined using the Aspen Plus simulator. Both models can satisfactorily be used to correlate the LLE of the systems. The provided data can be utilized in design and simulation of liquid-liquid extraction processes when dealing with salty water.

\section{References}

Saien, J., Mohammadi Sarab Badieh, M., Norouzi, M., Salehzadeh, S., 2015: Ionic liquid 1-hexyl-3-methylimidazolium hexafluorophosphate, an efficient solvent for extraction of acetone from aqueous solutions. J. Chem. Thermodyn. 91, 404-413.

Saien, J., Mohammadi Sarab Badieh, M., Norouzi, M., 2016: Experimental and theoretical assessing the salts effect on the equilibrium of water + acetone $+\mathrm{HMIMPF}_{6}$ ionic liquid system. Sep. Purif. Technol. 168, 199-208.

Buchbender, F., Meindersma, F.W., Haan, A., Pfennig, A., 2012: Simulation of aromatics extraction with an onic iquid in a pilotplantK" uhni extractor based on single-drop experiments. Chem. Eng. Sci. 82, 167-176.

Saien, J., Fattahi, M., Mozafarvandi, M., 2014: The impact of uni-univalent electrolytes on (water+ acetic acid+toluene) equilibria: Representation with electrolyte-NRTL model. J. Chem. Thermodyn. 74, 238-246.

Saien, J., Norouzi, M., Dehghani, H., 2013: The choice of solvent and liquid-liquid equilibrium for ternary water+ 2-

methylaziridine+ chloroform system: Experimental data and modelling. Fluid Phase Equilib. 338, 224-231.

Saien, J., Norouzi, M., 2011: Salting-out effect of $\mathrm{NaCl}$ and $\mathrm{KCl}$ on the liquid-liquid equilibrium of water+2-methylpropanoic acid+(1methylethyl)-benzene System at several temperatures. J. Chem. Eng. Data 56, 2892-2898.

For further questions and comments, please contact:

Marjan Mohammadi Sarab Badieh

phone: +32 (0) 4 366-3521

marjan.mohammadisarabbadieh@

student.ulg.ac.be 


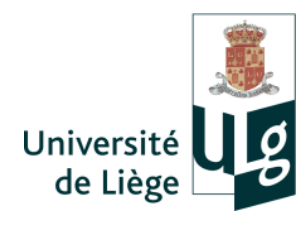

\title{
Extraction-Column Design for Highly Viscous Systems
}

\author{
Maria Chiara Quaresima
}

\begin{abstract}
Motivation
Change from fossil-based feedstock to biobased raw materials in chemical industry will lead to changes in the molecular structure of reagents and products. The oxygen content in bio-based feedstock is higher as compared to fossil starting material. Processing a component, which contains significant fractions of oxygen on molecular level, will lead to intermediates and products rich in oxygen as well. As a consequence, stronger molecular interactions due to polar interactions and hydrogen bonding will be present in mixtures. This in turn will lead to lower vapor pressures and higher viscosity of the systems. These changes in material properties need to be taken into account in process and equipment design.
\end{abstract}

Regarding separation processes, liquid-based separation such as extraction will foreseeably increase in importance compared e.g. to distillation. Solvent or liquid-liquid extraction is one of the options especially suitable in pharmaceutical and biotechnological engineering. In light of the future change in chemical feedstock, where bulk chemicals will increasingly be produced from biomass, solvent extraction will thus become more attractive for separation tasks. The design of industrial extraction columns based on lab-scale experiments and appropriate simulation tools allows reducing time and resources needed as compared to the conventional design based on pilot-plant experiments. The simulations of course require a deep knowledge of the details of the process.

\section{Past achievement}

Various phenomena and effects influence the extraction process, which need to be described accurately with appropriate mathematical models. This will allow predicting the behavior of the entire extraction column. Such a simulation needs to describe properly e.g. the concentration driving force between the continuous and the dispersed phase and the resulting transfer of the transferred component(s). The dispersed phase is present in the column as drop swarms. Within such a swarm, drops can coalesce and split as they pass along the apparatus, leading to variation of the drop-size distribution as a function of column height. This in turn means that the specific mass-transfer area will also vary. Since the sedimentation velocity depends on drop diameter as well, this also will vary, where sedimentation velocity is a very important parameter, because it determines the residence time of the drops in the column.

In previous work, a design method for extraction columns has been developed, which is based on the fact that the behavior of individual drops of the dispersed phase in an extraction column is influenced by a limited number of elementary processes, namely sedimentation, coalescence and splitting, as well as mass transfer. All these elementary processes interact and it is important to take these interactions properly into account for reliable extraction column design. Of course, the interactions among the droplets, the so-called swarm effect, as well as the interaction with the column internals is accounted for in the models. Also, the physical properties of the system strongly influence the process. In particular, the influence of viscosity has to be taken into account. Beyond this the drop behavior is also influenced by trace components. To cope with this variability, the models applied contain parameters that are fitted to results of experiments with individual drops of the original material system in dedicated lab-scale experiments.

These models are then combined in a simulation tool, called ReDrop (REpresentative DROPs), which follows the behavior of individual drops along their path through the column, taking the models and the parameters obtained from the experiments into account (Altunok et al., 2006). The main idea of ReDrop is to follow a sufficiently large number of drops along their path in the column accounting for all of the interconnected phenomena described before. 


\section{\begin{tabular}{c|c|c|}
\hline \\
$\begin{array}{c}\text { Université } \\
\text { de Liège }\end{array}$
\end{tabular}}

This approach is capable of describing extraction-column behavior to better than $10 \%$ accuracy, being time and resources saving compared to pilot plant experiments.

\section{Goal of the project and experimental plan}

The goal of this project is to extend the capabilities of ReDrop to account for the challenges described above resulting from the foreseeable shift towards bio-based feedstock. At first, the increased viscosity is to be considered, where the different models have to be validated and further developed, e.g. on sedimentation and mass transfer (Wagner et al., 2001). Validation of the models will be performed with single-drop experiments. Sedimentation velocity and mass transfer occurring in a single drop will be investigated with a single-drop cell as shown in Fig. 1 , where the central part consists of a conical glass tube used to levitate the drop by a counterflow of continuous phase.

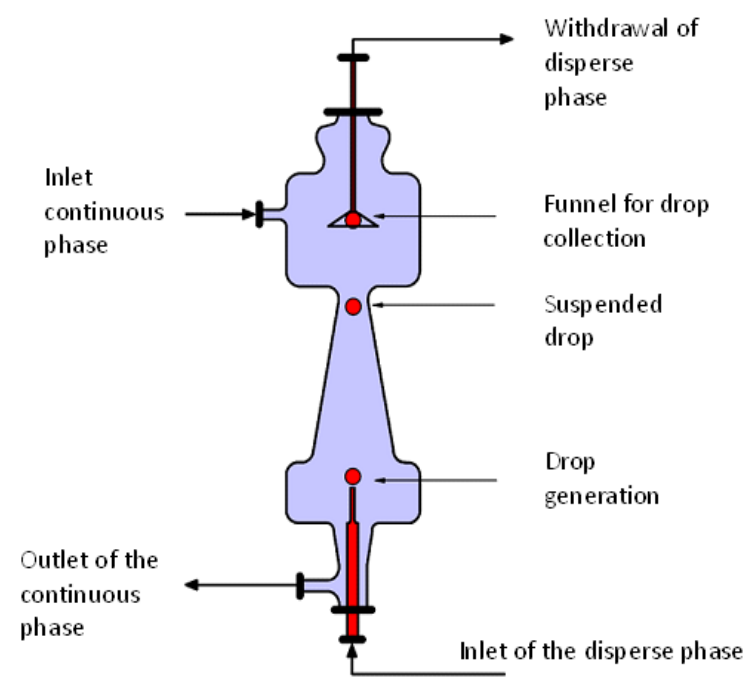

Fig. 1: Mass-transfer cell for single-drop experiments

Suitable material systems will need to be chosen. A standard EFCE system with low viscosity will be used to validate the installation. After validation, a system with higher viscosity will be investigated to analyze the effect of higher viscosity. The viscosity will be increased by adding suitable components like various polymers. As a further challenge, transfer-component behavior will be regarded as well, choosing components either with specific molecular interactions with the solvents or a higher molar mass. After single-drop investigations, the parameters obtained will be used in ReDrop simulations. As demonstrated in Fig. 2, ReDrop can solve the drop-population balance for each height element of an extraction column. For each height element, the drop-size distribution, the local hold up and the concentration of the transfer component in both phases is obtained and can be compared to corresponding column experiments.

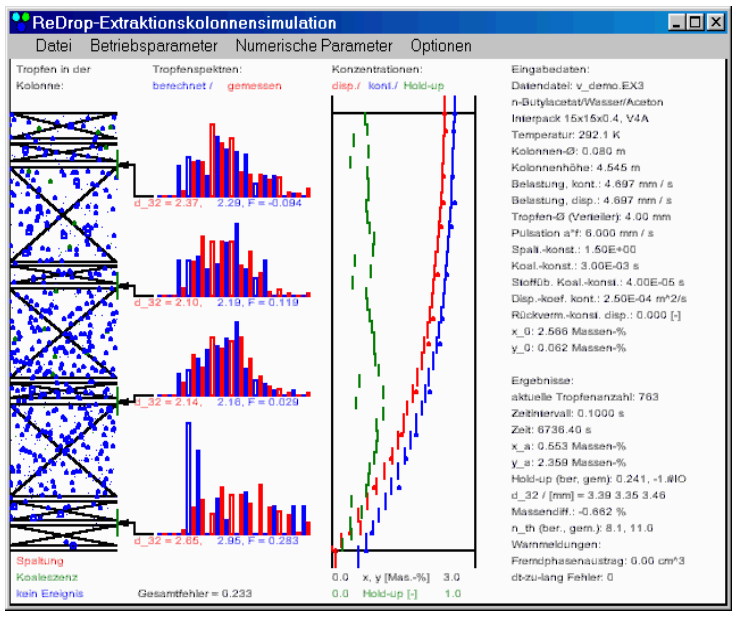

Fig.2: Example of ReDrop simulation

ReDrop also needs to be optimized, even if major portions of the existing code can be reused. The goal is to obtain a fast and reliable simulation tool that allows e.g. systematic optimization of operating parameters. A challenging task to which ReDrop will then be applied is e.g. in-situ extraction from fermentation broth where product removal needs to be performed to avoid product inhibition. Design of such kind of processes with ReDrop is a big challenge and can open interesting perspectives for separationprocess design.

\section{References}

Altunok, M., Grömping, T. and Pfennig, A., 2006; ReDrop - an Efficient Simulation Tool for Describing Solvent and Reactive Extraction Columns, Computer Aided Chemical Engineering, 21, 665-670

Wagner, I.; Stichlmair, J.; Wagner, B. I. The Effect of Viscosity on Mass Transfer in Pulsed Sieve-Tray Extraction Columns. Chem. Eng. Technol. 2001, 24, 616-619.

For further questions and comments, please contact:

Maria Chiara Quaresima

phone: +32 (0) 4 366-3559

mariachiara.quaresima@ulg.ac.be 


\title{
Université
de Liège
}

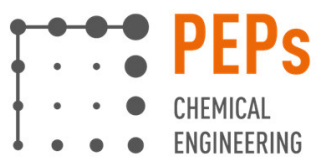

\section{Last Three Ph.D. Theses Defenses at TU Graz}

\author{
Andreas Pfennig
}

After roughly two years in Liège, still some Ph.D. students were supervised at TU Graz, who finally mastered their Ph.D. defenses on November 11. Their major research findings are described in the following in the order of their defenses.

\section{Dr.techn. Eva Kalvoda: Effect of Concentra- tion Gradients on Drop Sedimentation and Mass Transfer}

Eva Kalvoda has been investigating the interrelation between mass transfer and sedimentation, especially in a lab-scale cell, in which a concentration gradient in the continuous phase could be realized. The setup, which she has developed, realized, and used in her experiments, combines elements of the masstransfer cell developed at RWTH Aachen and that, which has formerly been used at TU Graz. The Aachen cell, which is now also established at the University of Liège (see p. 8), is characterized by a generation of individual drops of known volume with a nozzle and a computer-driven syringe, which is then kept floating for an arbitrary time in the countercurrent of the continuous phase. At TU Graz, mass transfer had formerly been characterized by drops, which were generated in series by a pump in combination with a nozzle, which were rising in a stagnant continuous phase. The residence time could be adjusted by varying the height of the sampling funnel.

In the cell of Eva Kalvoda, the drops were generated individually by a nozzle-syringe system, but were rising in a stagnant continuous phase, which had been filled into the cell with a dedicated concentration gradient (see Fig. 1). She then investigated systematically different cases of relative concentration gradients and evaluated the resulting drop concentrations in dependence on contact time and drop diameter with appropriate models.

Eva Kalvoda could clearly show that mass transfer behaves more complex as compared to the simple models usually applied. She was able to describe mass transfer inside the drop with a numerical shell model, where the effective diffusion coefficient depends on the sedimentation velocity. If the concentration gradient encountered by the drop exceeds a certain limit, mass-transfer rate is enhanced by a factor of 1.5. This significantly differs from the model of Henschke, which has previously been used in describing mass transfer in extraction columns (see e.g. Ayesterán et al., 2015). These observations nicely match findings by others (e.g. Henschke et al., 1999, Wegener et al., 2014), which indicate that mass-transfer induced convection at the interface enhances mass transfer and reduces sedimentation velocity. This new model will be used ReDrop, our simulation tool for extraction-column design, in the future, to better describe drop behavior.

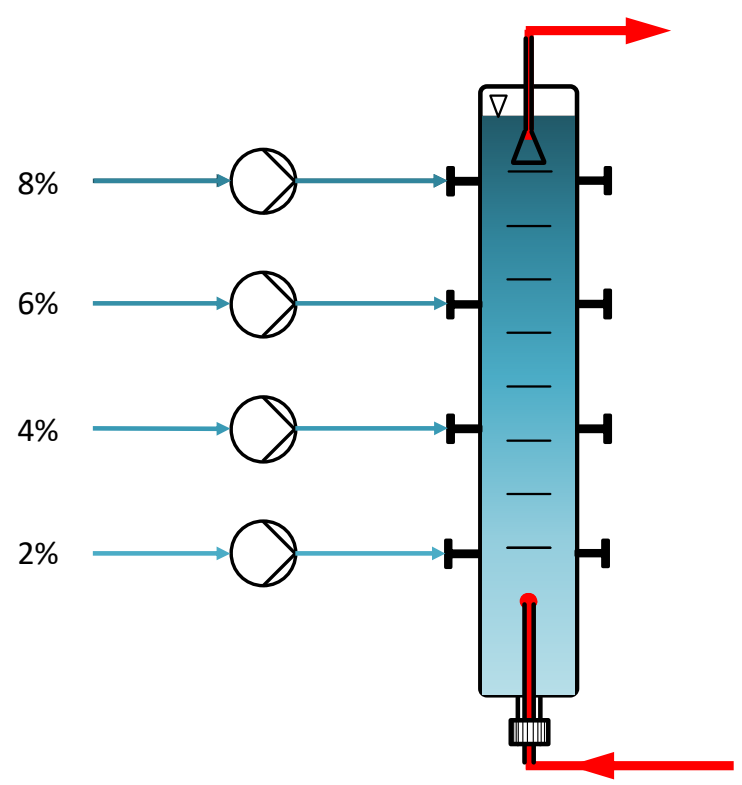

Fig. 1: Single-drop mass-transfer cell of Eva Kalvoda with concentration gradient.

\section{Dr.techn. Jan Bernd Bol: Accounting for Costs and Selectivity in Optimal Experi- mental Design of Phyto-Extraction Experi- ments}

Jan Bernd Bol has started his work already in Aachen, continuing on the topic of phyto ex- 


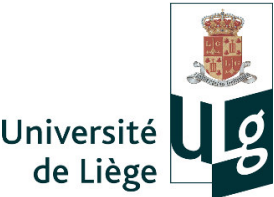

traction, building on the previous research by Dirk Delinski. Here solids extraction or leaching is applied to plant-based material, to recover specific plant components like pharmaceutically active components or spices. The basic idea of his thesis is that in applying ordinary modelbased experimental analysis (MEXA) it is assumed that the parameters of the model are actually the desired quantities. Thus, the accuracy of determining these parameters is taken as measure in judging the uncertainty obtained with the experiments.

This view unfortunately neglects that the model parameters are rarely the final result to be obtained. Instead, the models with their parameters are means to optimize performance of processes with respect to the final product costs. This of course has to be accounted for in optimal experimental design. Jan Bernd Bol showed that accounting for the accuracy of the cost optimum leads to different optimal experimental conditions as compared to those, which optimize model-parameter accuracy. One of the major challenges of this thesis was to differentiate clearly between the parameters of the lab-scale experiments performed in a standardized setup (see Fig. 2) and those parameters found in the process of cost optimization. For example the ratio between extractant and plant material is relevant in the lab-scale experiments but of course also in the optimized technical process. The optimum for the industrial-scale process generally will differ from that obtained for the optimal lab-scale experiments. This distinction led to quite some numerical effort in the optimization procedure.

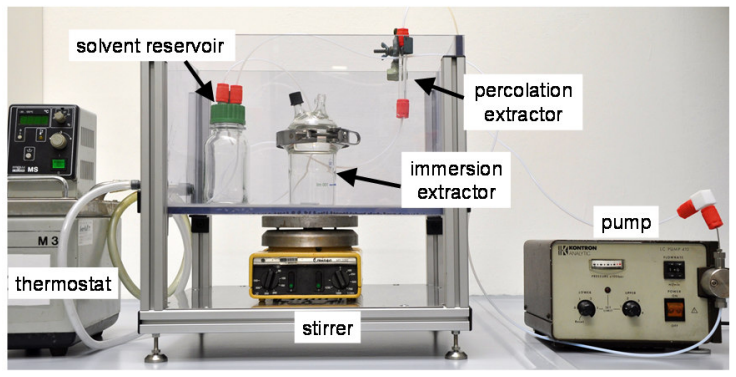

Fig. 2: Standardized lab-scale equipment for design of solids extraction and leaching processes.

Jan Bernd Bol argues that it is to be expected that the difference in experimental conditions optimized for parameter accuracy will differ from those for cost optimality especially, if a larger number of process variables are ac- counted for - as is usually the case. Finally he also included selectivity into his considerations, allowing to account for the details of the extraction process, i.e. differentiating between equilibrium-based and kinetic selectivity.

\section{Dr.techn. Anton Markus Reiter: Extending the Method of Surrogates to Bio-Based Fuels and Mixtures with Fossil Fuels}

The basic idea of substituting fuel mixtures by surrogates has been applied in the group of Ass.Prof. Dr.techn. Thomas Wallek since quite some time. The major idea is to use a mixture of real components as a substitute for the very complex mixture encountered in real diesel or gasoline. Using a mixture of real components instead of the frequently encountered pseudocomponents has the advantage that these mixtures can be prepared and investigated in the lab for their physical and combustion properties.

Challenges arise in selecting the optimal mixture out of a given collection of candidate components such that the desired physical and combustion properties are optimally matched. Unfortunately, the potential candidates are limited in number, especially, if the price for preparing the desired mixture is accounted for as selection criterion. Especially, if the surrogate mixture is to be used in real motor tests, large quantities are required, leading to certain constraints.

Anton Reiter has first of all carefully selected the methods, with which the physical properties are calculated so as to best match with experimental results of pure components and mixtures. In a next step an improved method for selecting the components in the surrogate mixture and for fitting their composition in that mixture has been developed. Anton Reiter then has been proven that this method results reliably in the best optimum mixture of the candidate components for any predefined number of surrogate components.

In applying his method to biodiesel he has shown that biodiesel itself can be depicted with a relatively small number of components mainly matching the basic molecular parameters found e.g. in different FAME (fatty acid methyl ether). In a last step, he demonstrates that also the properties of mixtures between fossil and biobased fuels can be described based on surrogate mixtures. 


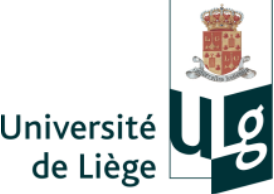

In cooperation with OMV, the Austrian company in the area of oil and refinery including gasoline stations, surrogates have been prepared and their physical properties determined. It turns out that the optimized surrogate for a given fuel nicely matches with the predicted properties like boiling-point curve and density, but that these properties also match those of the fuel that was to be mimicked. Thus, it has been shown that the method of surrogate mixtures can accurately be applied to fossil and biobased fuels as well as their mixtures.

\section{The Stay in Graz}

Of course, it has also been nice to be back in Graz after some time. The city of Graz is very active and emanates a very specific spirit of creativity and liveliness. This led Graz to become UNESCO City of Design in 2011.

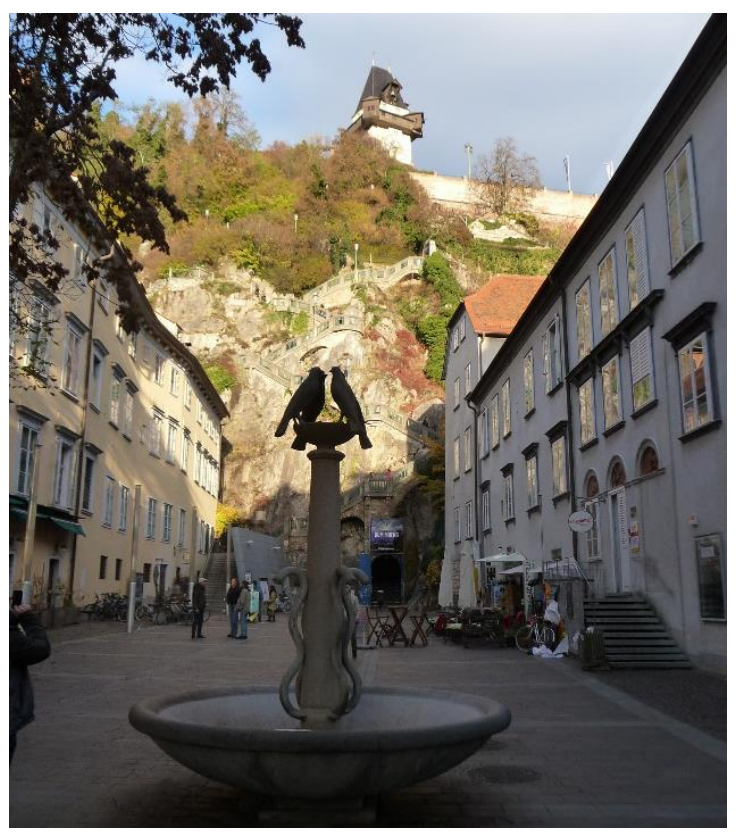

Fig. 3: Grazer 'Schlossberg' with clock tower.

What is especially nice for visitors is the relatively compact city center, where essentially every point of interest (see e.g. Fig. 3) can be reached by foot or by the tram, which in Graz is called 'Bim', presumably based on the ringing of the tram, which one hears, whenever some pedestrians do not leave the tracks quickly enough, if the tram approaches. In the innermost city center, the tram can even be used free of charge.

With the defenses of Eva Kalvoda, Jan Bernd Bol and Anton Reiter all Ph.D. students that I still supervised at TU Graz have thus finished their formal Ph.D. procedure. Nevertheless close interaction still remains with TU Graz in the area of molecular thermodynamics with Ass.Prof. Dr.techn. Thomas Wallek, who is developing a thermodynamic model for strongly interacting molecules based on the concept of discrete modelling, in which the discrete state of individual molecules and their interactions are taken into account when formulating the thermodynamic relations. This method very fundamentally considers all molecular interactions in their full three-dimensional structure. Thus several simultaneous interactions, which may lead to especially strong association, can be described in principle. Since this approach very nicely complements my previous research on 3D thermodynamics, this link to TU Graz will remain strong - besides possible future interactions in the context of projects, which meanwhile have been submitted by colleagues in the area of biotechnology.

\section{References}

Ayesterán, J., Kopriwa, N., Buchbender, F., Kalem, M., Pfennig, A., 2015: ReDrop - A Simulation Tool for the Design of Extraction Columns Based on Single-Drop Experiments. Chemical Engineering and Technology, 38(10), 1894-1900.

Bol, J.B., 2016: Optimale Versuchsplanung unter Berücksichtigung der Prozesskosten am Beispiel der Phytoextraktion. Ph.D. thesis, TU Graz.

Henschke, M., Pfennig, A., 1999: Masstransfer enhancement in single-drop extraction experiments, AIChE J. 45, 2079-2086.

Kalvoda, E., 2016: Einfluss von Konzentrationsgradienten auf das Verhalten von Einzeltropfen in Extraktionskolonnen. Ph.D. thesis, TU Graz.

Reiter, A.M.: Thermodynamische Beschreibung von fossilen und biogenen Treibstoffen. Ph.D. thesis, TU Graz.

Wegener, M., Paul, N., Kraume, M., 2014: Fluid dynamics and mass transfer at single droplets in liquid/liquid systems. Int. J. Heat Mass Transfer 71, 475-495.

For further questions and comments, please contact:

Andreas Pfennig

phone: +32 (0) 4 366-3521

andreas.pfennig@ulg.ac.be 




\section{Advantages of Centrifugal Extraction}

\author{
Andreas Pfennig
}

\section{Challenges in Extraction}

Due to the foreseeable change in feedstock for chemical processes from fossil resources to biobased starting material, it is to be expected that the viscosity of intermediates and products will increase. Also, since biomass is solid in nature, remainders of the solid starting material are expected also in subsequent process steps, which typically may lead to problems like crud formation. Since these systems will lead to increasing problems with phase separation, applying centrifugal forces for enhancing phase separation needs to be regarded. The simulation tool currently developed by David Leleu (see p. 4) does thus not only account for an arbitrary number of dispersed phases with their individual drop-or particle-size distributions and a variability in interactions that can be accounted for, but has also be designed to account for centrifugal forces as well.

\section{First Results}

As shown in Figs. 1 and 2 the simulation model for settler design allows accounting for centrifugal forces, drop-size distributions as well as coalescence already during sedimentation, which was not the case in the original design tool developed by Henschke (Henschke et al., 2002).

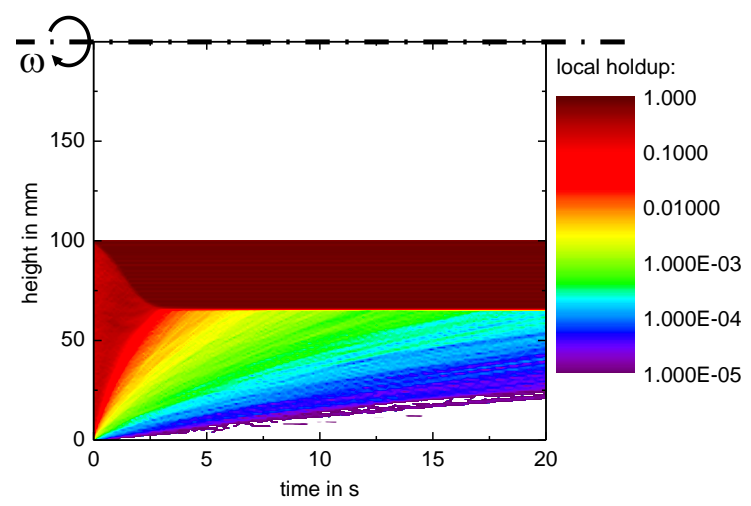

Fig. 1: Polydisperse drop-size distribution in a centrifugal extractor at $1000 \mathrm{~min}^{-1}$ and $200 \mathrm{~mm}$ rotor radius, of which only the outer $100 \mathrm{~mm}$ are filled with liquid.
Fig. 2 demonstrates that the current tool allows also to evaluate the critical parameter of remaining dispersed-phase fraction in the exiting continuous phase, which is a key design parameter. It turns out, as shown in Fig. 1, that it is beneficial, to leave the inner volume of the rotor empty, because then the dispersion experiences stronger centrifugal forces. It turns out that the throughput can even be higher, even though the available cross-sectional area is reduced, because the residence time required for complete separation is significantly reduced by this measure.

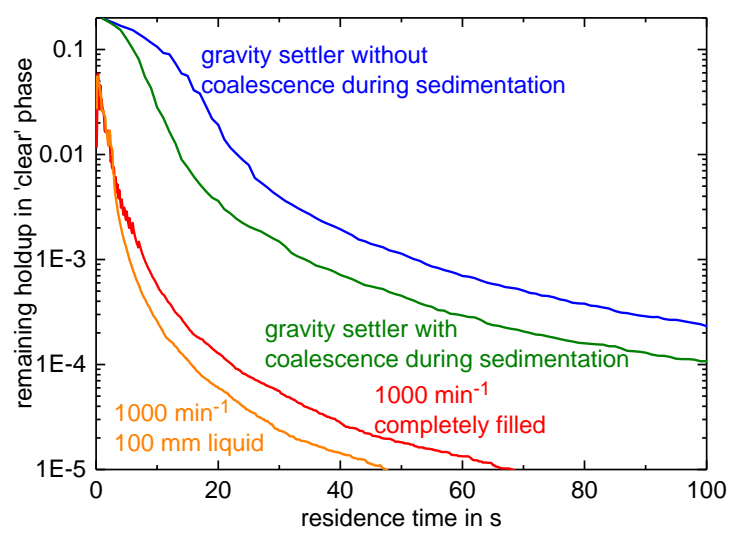

Fig. 2: Remaing fine dispersion after treatment in gravity and centrifugal settlers

\section{References}

Kopriwa, N., Pfennig, A., 2016: Characterization of Coalescence in Extraction Equipment Based on Lab-Scale Experiments. Solvent Extraction \& Ion Exchange, 34(7), 622-642.

Henschke, M., Schlieper, L.H., Pfennig, A., 2002: Determination of a coalescence parameter from batch-settling experiments. Chem. Eng. J. 85(2-3), 369-378.

For further questions and comments, please contact:

David Leleu

phone: +32 (0) 4 366-3559

dleleu@ulg.ac.be 


\section{\begin{tabular}{c|c|} 
Université \\
de Liège
\end{tabular}}

\section{Evaluation of Exergy Applied to Alternative Biobased Processes}

\section{Background}

Due to the international goal to reduce the use of fossil resources and the currently relatively large volatility of crude-oil price, biobased chemical products may become increasingly important in the future. Since a wide variety of processes fundamentally differing in process concept have been proposed, the question arises, if it is possible to gain some fundamental insight into the efficiency of the proposed processes. It appears that exergy may be a variable, which allows such an evaluation on a level of detail, which can be chosen freely. Exergy is especially attractive for such an evaluation, because it measures the value of exergy and is thus closely related also to the economic value of streams. Also exergy losses in a process define the minimum energy required for operating the process.

\section{Exergy as Measure of Efficiency}

Dr.-Ing. Philipp Frenzel has shown in his studies that chemical exergy is the major contribution to the exergy of streams and that for such fluxes it is a state variable. Conversion between different chemical compounds can thus be described primarily by the net change in chemical exergy of the reaction. The chemical exergy is thus shown in Fig. 1 for various components. It is obvious that biobased components, which are higher in oxygen content as shown in Fig. 2, have a lower chemical exergy than fossil counterparts. Philipp Frenzel has also shown that chemical reactions are exergetically especially feasible, if the net change of exergy across the reaction is zero or negative. Thus, it is to be expected that in the future also intermediates and products will become increasingly important, which have higher oxygen content on molecular level.

Fig. 2 shows that todays' products as black circles, where the size of each circle is proportional to the production rate of that component, very nicely match with that of fossil resources. On the other hand, if these products are to be obtained from biobased feedstock, oxygen has to be removed. Fig. 2 also indicates options to achieve this, where the most promising option is to add the energy-rich hydrogen followed by splitting off water. This is the only step, which does not lose the carbon, which has just been collected via the biomass, nor does it lead to components close to the carbon corner, which would mimic the composition of coal.

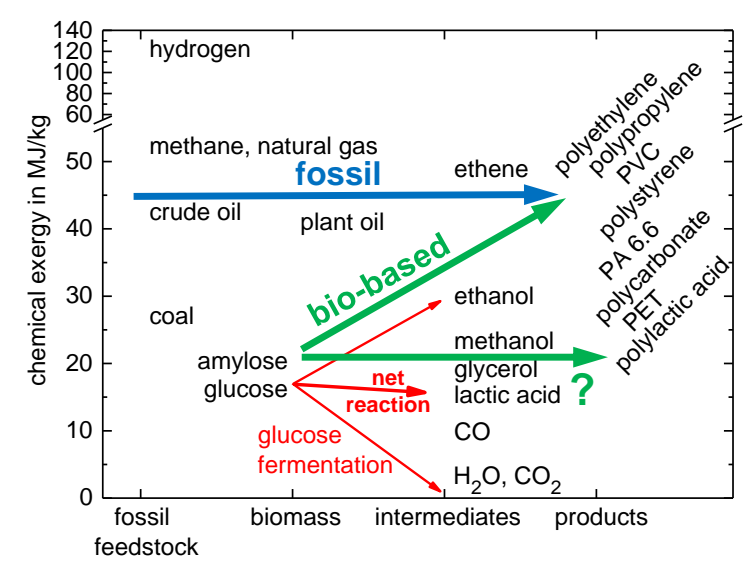

Fig. 1: Chemical exergy for various components.

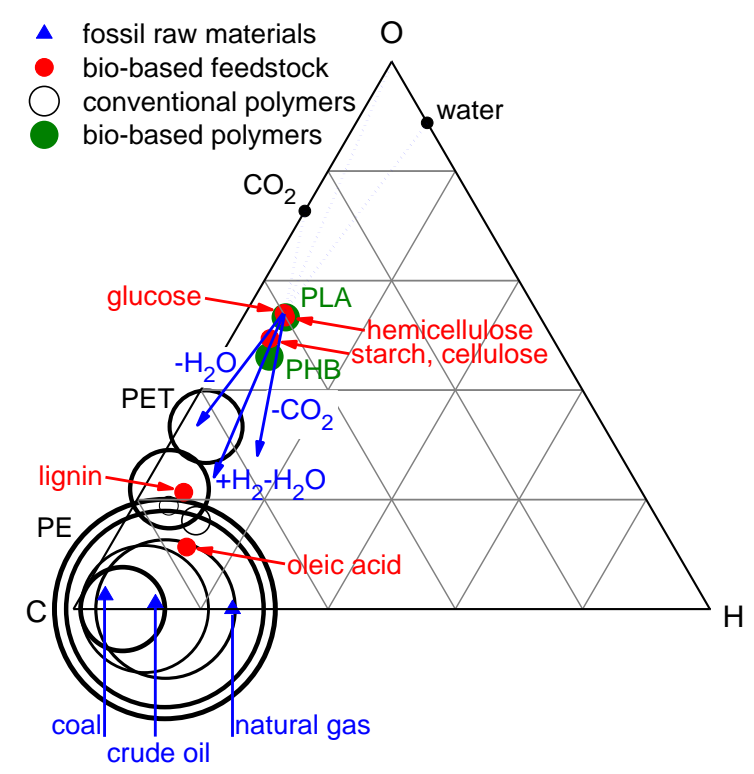

Fig. 2: Mass-based composition of various components with respect to $\mathrm{CHO}$. 


\section{\begin{tabular}{|l|l|l|}
\hline & \\
\hline
\end{tabular}}

On a next level of refinement, exergy can be used to evaluate processes also accounting for process losses. Philipp Frenzel has evaluated a variety of processes for conversion of biomass to various polymers, because they are the largest products of chemical industry. The comparison was performed with ExergySim, a tool he developed based on Matlab. He has compared the processes with those starting out from fossil resources and shown that some of the biobased processes lead to similar exergy losses as compared to the fossil counterparts. This applies especially for polymers with some oxygen content like PET (polyethylene terephthalate) or PLA (polylactic acid). On the other hand, biobased processes for production of e.g. polyethylene (PE) require significantly more energy as compared to fossil-based options. Nevertheless, the exergy required for the oxygen-containing polymers is always higher than that of e.g. PE from crude oil. Since as argued above, an increase in oxygen content of products is to be expected in the future, this means that the overall energy demand of the chemical industry will increase.

Since it is quite tedious to evaluate the exergy losses for real chemical processes, accounting for all changes in composition, temperature, and pressure, Philipp Frenzel has also developed a short-cut method, which allows determination of an approximate exergy loss of a process. To derive this short-cut method, simplifying assumptions had to be made, e.g. assuming ideal heat integration and that the separation of mixtures can be performed with some pre-defined simplified separation sequences. Philipp Frenzel has shown that this short-cut method may lead to some deviation of the absolute value of exergy loss for a regarded process. On the other hand, comparing the relative exergy losses between competing processes, it turned out that the order remained unchanged for the examples investigated. Thus, this short-cut method allows fast evaluation of process options with respect to exergy losses. Due to the assumptions made for deriving this short-cut method, this can only be used to eliminate obviously inefficient alternatives from the list of available options.

Thus it turns out that exergy can be applied on various levels of detail:

- starting out from a very general perspective, regarding only the molecular oxygen content in the evaluation,
- accounting for the chemical exergy of individual components,

- considering additionally estimated process losses based on a short-cut method,

- evaluation of the process losses based on a first sketch of the unit operations combined in the process with estimated temperatures and pressures,

- and finally the exact evaluation of exergy losses also taking into account the losses of individual pieces of equipment.

This shows the versatility of the exergy evaluations.

Also, Philipp Frenzel evaluated the land area, which is required in developed countries to produce the required biomass for supplying typical amounts of chemical products and found that roughly 300 to $600 \mathrm{~m}^{2} /$ capita are required, which appears manageable but is significant as compared to today's world average value of $7000 \mathrm{~m}^{2} /$ capita for food production.

\section{References}

Frenzel, P., 2014: Bewertung von Syntheserouten auf Basis von Exergiebilanzen. Ph.D. thesis, RWTH Aachen.

Frenzel, P., Pfennig, A., 2016: Methodik zur schnellen Bewertung von Syntheserouten auf Basis von Exergiebilanzen. ProcessNet-Jahrestagung und 32. DECHEMAJahrestagung der Biotechnologen, 13.15.9.2016, Aachen, Germany.

Frenzel, P., Hillerbrand, R., Pfennig, A., 2014: Exergetical Evaluation of Biobased Synthesis Pathways. Polymers, 6(2), 327-345.

Frenzel, P., Hillerbrand, R., Pfennig, A., 2014: Increase in energy and land use by a biobased chemical industry. Chem. Eng. Res. Des. 92, 2006-2015.

Frenzel, P., Fayyaz, S., Hillerbrand, R., Pfennig A., 2013: Biomass as Feedstock in the Chemical Industry - An Examination from an Exergetic Point of View. Chem. Eng. Technol. 36(2), 233-240.

For further questions and comments, please contact:

Andreas Pfennig

phone: +32 (0) 4 366-3521

andreas.pfennig@ulg.ac.be 


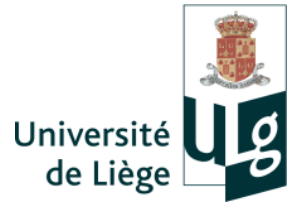

\section{Cascaded Option Trees used for Systematic Selection of Reactive Extractants}

\section{Starting Point}

In several projects in cooperation with industry and colleagues from other universities, the goal was to select and design optimal downstream processing options after a fermentation step for primary product recovery. This first downstream operation should preferably be performed in-situ to reduce significantly the product concentration to avoid the typical product inhibition. The resulting challenge in the cooperation projects BISON, Carboxyfun, and others was to efficiently and systematically evaluate the very many different options and to find a way to clearly communicate the results to the project partners. This led to the derivation of the method of cascaded option trees.

\section{The Method}

An example option tree is shown in Fig. 1, where the option-tree method is applied to an extractive purification step. First, the various options are explicitly noted and then evaluated systematically with respect to feasibility, where a color code simplifies presenting and discussing the results. As shown, different levels can be regarded, where only two levels are shown, including the principal distinction between physical and reactive extraction on one level and the selection of reactive extractant in combination with the diluent as second level. The individual criteria, with respect to which the various options have been evaluated, are associated with the columns, in which the result is depicted as color code. The overall feasibility of an option is noted to the left of that option with the same color code. Any option, which is infeasible with respect to a criterion, can be excluded from all future evaluations. It is also apparent, which options remain feasible, and some idea on the overall feasibility is easily recognized.

The systematic progressing through the criteria also allows optimally structuring the work efforts for evaluating the criteria, since first, those criteria should be evaluated, which will presumably lead to the most restrictive results.
In the case regarded, i.e. where reactive extractants for product removal from a fermentation broth were regarded, the most critical criterion is the separation behavior of the two phases after the extraction step. It turned out that in one of four cases, to which this method was applied, it was not possible to find a process window that would allow a continuous operation of the extraction process.

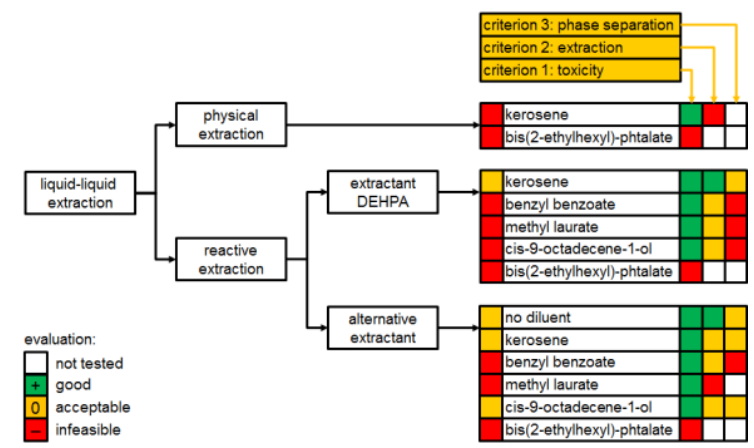

Fig. 1: Cascaded option tree applied to extraction from a fermentation broth

Unfortunately, the phase-separation behavior strongly depends on $\mathrm{pH}$, where the extraction is performed, where $\mathrm{pH}$ in turn is a key parameter in the extraction performance as shown in Fig. 2. At the same time the concentration of D2EHPA (di-(2-ethylhexyl) phosphoric acid) in the diluent kerosene determines the $\mathrm{pH}$ at which essentially complete extraction is achieved. Thus in a first step, the $\mathrm{pH}$-range has to be determined, in which the extraction is feasible. Since in-situ separation is desired, the $\mathrm{pH}$ should lie in a range around 7 , because this is feasible for the microorganisms. Then the concentration of D2EHPA in the diluent can be selected, where increasing the concentration increases also the capacity, where a higher capacity allows lower flowrates of the reactive extractant. As can be seen in Fig. 2, any D2EHPA concentration above $2.5 \%$ will lead to essentially complete extraction in the desired $\mathrm{pH}$-window. Higher D2EHPA concentrations, while being beneficial for the capacity, will lead to lower $\mathrm{pH}$ required for re-extraction, meaning larger amounts of acid and base to shift be- 
tween the $\mathrm{pH}$-values of extraction and reextraction. Since higher concentrations of D2EHPA also lead to higher viscosity of the extraction phase, the operation of the extractor and especially the phase separation will in general become more difficult. This shows that the designing engineer has to choose the concentration of D2EHPA as well as the corresponding $\mathrm{pH}$-values for extraction and reextraction by finding an optimal compromise between process feasibility and economic performance.

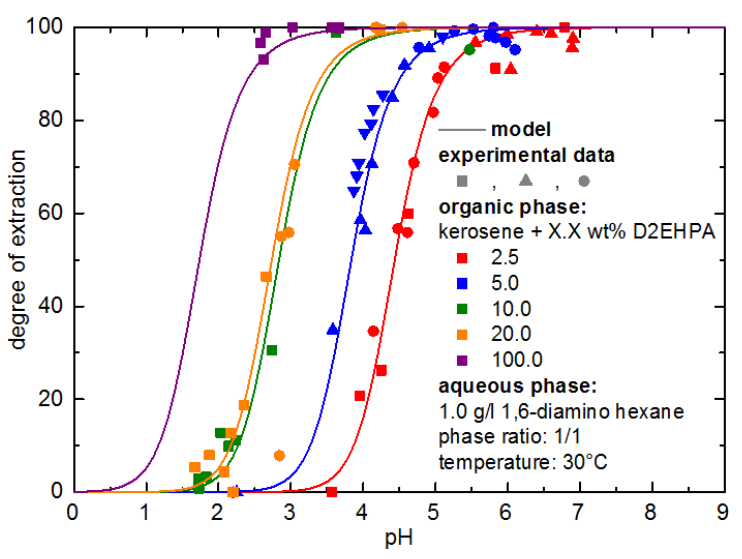

Fig. 2: Reactive extraction of a diamine from fermentation broth with D2EHPA in kerosene as reactive extractant

After these first fundamental choices with respect to reactive extractant, diluent, and $\mathrm{pH}$ range have been guided by the option-tree method, the method can be used cascading through all levels of process and equipment design. On the next level of detail, also different options for the direction of dispersion, the flow rates, the extractor type, and other process parameters can be regarded. More criteria can be evaluated as well, which at later stages of process design include the fate of all components participating in the process, so that e.g. the reactants stay in the fermentation broth and only the product is removed.

One strength of this method is the flexibility with respect to the methods used for the individual evaluations of the criteria. This can range from expert opinions to detailed simulations or experiments. Another strength is the ease with which it allows very clear presentation of the remaining feasible options to project partners, which forms a good basis for further discussions in a project or process-design team. As described, the option trees can be used stepping through different levels of detail.
This cascading way of applying the option trees has the advantage that even if under certain conditions one option should later turn out to be infeasible, the second-best option on the next higher level can directly be realized and then worked out further.

The clarity of the graphic representation of the results also eases discussions in a project team with respect to very fundamental options. Often, first microbiology and biotechnology experts have worked out a production process to a certain level of detail, before the engineer responsible for the downstream process is consulted. This leads to the situation that all biotechnological parameters are essentially fixed, even though parameters like nutrient composition or buffer system in the fermentation will have a fundamental influence e.g. on phase separation. Thus, it may be required to convince the biotechnologist to consider e.g. a different buffer system. In that situation the representation with the option trees allows to clearly visualize the situation and the chances for alternative options.

Meanwhile the cascaded option trees have also been used in quite different contexts, i.e. for systematic model design in our own work.

\section{Acknowledgements}

This work including the preparation of the diagrams was mainly performed by Andreas Bednarz, Bettina Rüngeler, Peter Scherübel, and Markus Schmidt.

\section{References}

Bednarz, A., Rüngeler, B., Pfennig, A., 2014: Use of Cascaded Option Trees in Chemical-Engineering Process Development, Chem. Ing. Tech. 86(5), 611-620.

Bednarz, A., Rüngeler, B., Scherübel, P., Schmidt, M., Pfennig, A., 2016: Systematic Downstream Development, Optimization and Equipment Design for Biobased Products and Processes. ProcessNetJahrestagung und 32 . DECHEMAJahrestagung der Biotechnologen, 13.15.9.2016, Aachen, Germany.

For further questions and comments, please contact:

Andreas Pfennig

phone: +32 (0) 4 366-3521

andreas.pfennig@ulg.ac.be 


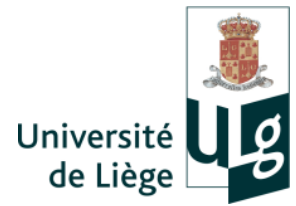

\section{Teaching and Research on YouTube}

\author{
Andreas Pfennig
}

\section{Motivation}

In the past, for the various lectures held at the various universities individual lecture manuscripts have been worked out, which is apparently quite some effort. Most of the material developed during the last years has been in English. At the same time, expert topics have been dealt with in workshops, for which corresponding educational manuscripts have been written. But unfortunately, many research results are presented solely in scientific publications, which have their very specific style. This style is of course required for ensuring high scientific standards. On the other hand, much information is actually lost, which results e.g. from tests that have been performed but failed, just to mention one example. Thus actually a big book of knowledge is desired, which combines the fundamental basics, which are taught in standard textbooks, but which also accounts for the most recent findings, including the insights usually not communicated in scientific publications.

To this end, several chapters on thermal separation processes from different manuscripts have been combined, which deliver the very basics found in any textbook, but at the same time cover also our latest results in research. This textbook is continually growing as we work through the chapters bringing them into a sort of final form. Besides the very fundamental chapters on distillation, extraction, absorption, etc. also more specialized topics like simulated-moving bed chromatography, various hybrid processes, and drop-based design of extraction equipment are included. The goal of this effort is to publish the individual chapters online on our website.

Such a public availability of course requires careful consideration of copyright issues, which apparently slows down the publication process somewhat. Here actually active input and support from companies, which can supply corresponding photographs or diagrams, which are suitable for teaching purposes in visualizing e.g. column internals, equipment in operation, and also more complex aspects like internals after some operation would be highly welcome. For the latter aspect, we can also guarantee that we do not mention the source, if desired...

One specialty of the course material is some focus on generalized description of separation processes. This chapter resulted from the realization that an increasing number of topics should be included even in the most basic lecture on separation processes. This can only be achieved, if some generalization is realized, which can then be applied to many unit operations. This chapter thus among others describes the basis for the McCabe-Thiele method in a very generalized way, which allows easy description of counter-current processes with a wide variety of special features like side withdrawals, various types of specific feed options, etc.

In interaction with some companies, it has e.g. been found that it is important to stress the fundamental assumptions, which are required to derive the linear operating lines of the McCabe-Thiele method. It has e.g. to be ensured that the flow rates of the phases regarded are constant along any process section and that the flowrate of a regarded component is described by this flowrate multiplied with the chosen concentration measure. Thus, in one case overall flowrates and mole or mass fractions are appropriate, while in other cases the carrier flowrates together with loads of transfer component in either phase have to be regarded to ensure that the assumptions are fulfilled. Also, the choice of molar or mass-based description may be guided by considering the assumptions. Even a volumetric description in combination with (volume-) concentrations may be the appropriate choice in some cases. Only after appropriately choosing this 'reference system of variables', the operating lines are straight so that the usual step construction can easily be realized - which of course requires that in describing the equilibrium the corresponding concentration measures are applied. If the assumptions are not fulfilled, in some unfortunate case grossly wrong numbers of 


\section{\begin{tabular}{c|c|c|} 
Université \\
de Liège
\end{tabular}}

theoretical stages may result - as was the case in one of the practical applications.

At the same time, it has been realized that on the one hand it is desired by students to have videos of the lectures available. On the other hand, supplying just video recordings of the lectures will lead to a bad quality of the videos, but nevertheless results in some effort. As a consequence, the lectures are now recorded in good quality together with the IFRES (Institut de Formation et de Recherche en Enseignement Supérieur), who supply a proper studio environment as shown in Fig. 1. Is has proven beneficial to display the PowerPoint slides on a large TV-screen, with which the lecturer can easily and directly interact, directly pointing and explaining the slides. On the other hand, derivations formerly reproduced on the blackboard are now written on the convertible notebook with a digital pen and the Windows journal program. This also sufficiently slows down the derivations, so that even students who learn by taking detailed notes are supported in their learning efforts. The voice is recorded with a clip-on microphone and a digital 24bit-recorder, which eases level adjustment and maximizes signal-to-noise ratio.

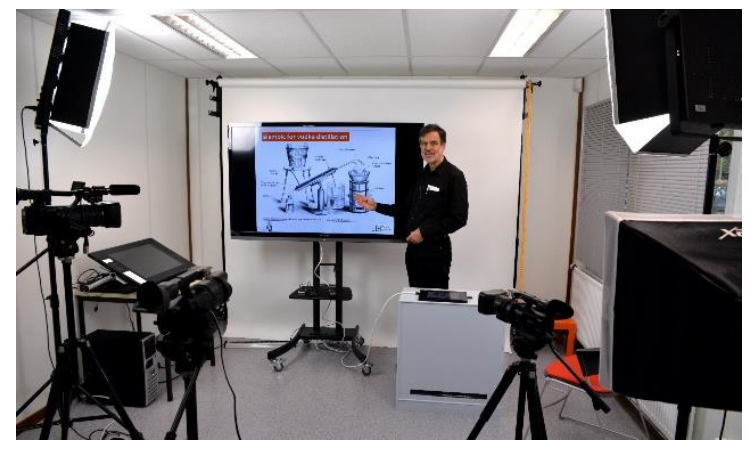

Fig. 1: Studio environment for lecture recording (photo reproduced with permission: (C) Olivier Borsu, IFRES - ULg, 2016)

The videos are then edited and uploaded to YouTube, where they are included in proper order in a playlist, to which the link is given in the references. An impression of the final result is presented in Fig. 2, which nicely shows how easily the interaction with the presented picture is possible. Especially problems with illumination and exposure, which are typical in other recording settings, are avoided. The videos until now cover more than ten hours of lecturing, where especially those lectures have been left out, which contain e.g. pictures from col-

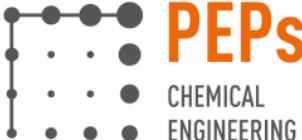

umn internals, for which clarifying the copyright issues needs time. Some companies have already supplied corresponding picture material, for which they grant the right to include them in the manuscript as well as in the YouTube videos. We are currently trying to obtain more material, which may also include videos, which are shown in the lecture videos.

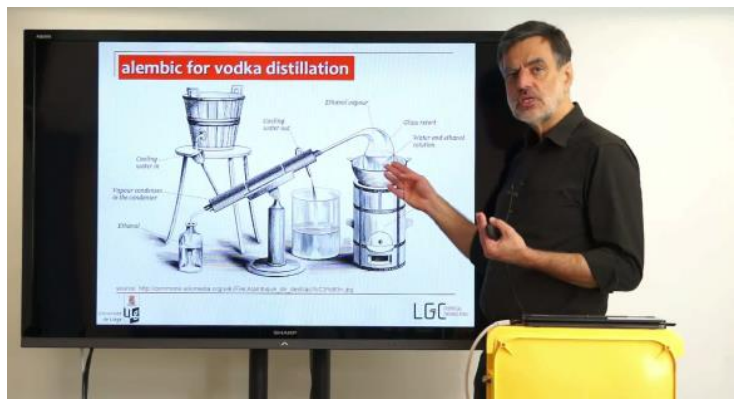

Fig. 2: Snapshot from an edited video

A side effect of these recordings is that also the slides are carefully checked and as far as possible inconsistencies removed. This includes also careful rethinking of the logical order of the material presented. This does not mean that the previous lecture material contained errors, but the consistency was not always optimal. Thus, also the 'ordinary' lecturing strongly benefits from this recording effort. The manuscript is correspondingly optimized chapter by chapter along the way and will be supplied on our new website, which is currently under construction.

As already mentioned, contributions of photos and videos are welcome. Finally it should be mentioned that it is desired to include also expert knowledge in guest videos.

\section{References}

Pfennig, A.: Thermal Unit Operations. YouTube playlist:

https://www.youtube.com/playlist?list= PLEivQtB6FVkfUbs81p-i42FtjEl 2NWZY

Pfennig, A.: Internet Platforms for Education on Sustainability. 8th Conference on Engineering Education for Sustainable Development, 4.-7.09.2016, Bruges, Belgium

For further questions and comments, please contact:

Andreas Pfennig

phone: +32 (0) 4 366-3521

Andreas.Pfennig@ulg.ac.be 


\section{Lecturing in Bangkok and Oman}

\section{Andreas Pfennig}

Meanwhile it is a good tradition to teach in Oman and Bangkok. These teaching and training visits have been realized also in 2016.

\section{TGGS in Bangkok}

The first teaching visit this year was to the Thai-German Graduate School (TGGS) in Bangkok, which started end of March. The contact to TGGS is well established and originates from the time in Aachen, from where TGGS was initiated. TGGS is realized as a faculty within KMUTNB (King Mongkuts University of Technology North Bangkok) with a variety of different specializations, one of which is Chemical and Process Engineering (CPE).

At TGGS, the course delivered for students focused on advanced separation processes like reactive extraction and rectification, but also included such topics at drop-based modelling of separation processes (see Fig. 1). This course was then followed by an industry workshop, in which also demanding design challenges in chemical engineering were discussed (see Fig. 2).

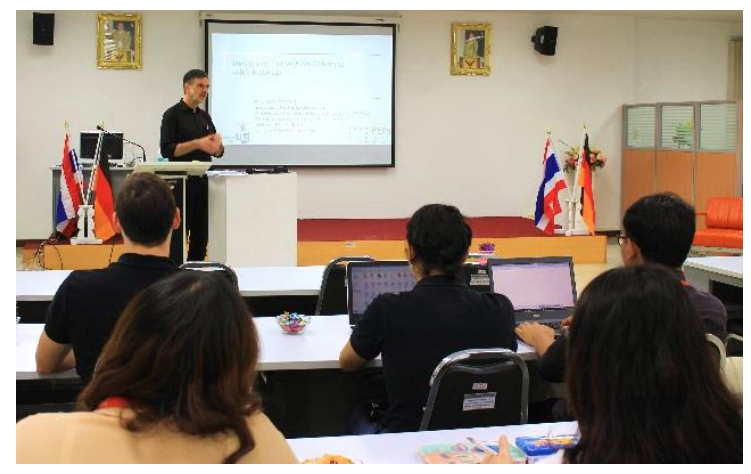

Fig. 1: Advanced-separation course at TGGS in Bangkok

The stay in Bangkok was perfectly organized by Dr. Tawiwan Kangsadan, head of the CPE department. What is special about the stays at CPE is the always very friendly atmosphere as well as the very supportive environment, which is highly appreciated.

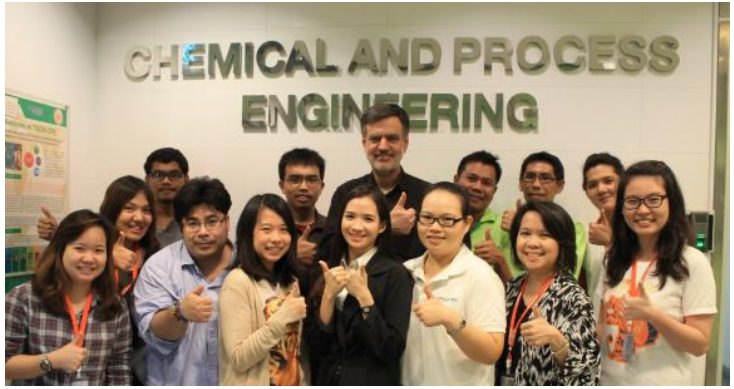

Fig. 2: Thumbs up after the industry workshop

\section{GUtech in Oman}

The second visit was in May 2016 to the German University of Technology in Oman, which is another offshoot of RWTH Aachen, which is headed by a close former colleague, Prof. Michael Modigell. At GUtech the fundamental course on thermal separation processes was presented. As can be seen in Fig. 3, it is characteristic in Oman that mostly women are seen in the lectures, even if also some men are taking the course. The organization of all the details by Dr. Najah Al Mhanna was perfect, so that also the visit to GUtech was very agreeable and will be repeated.

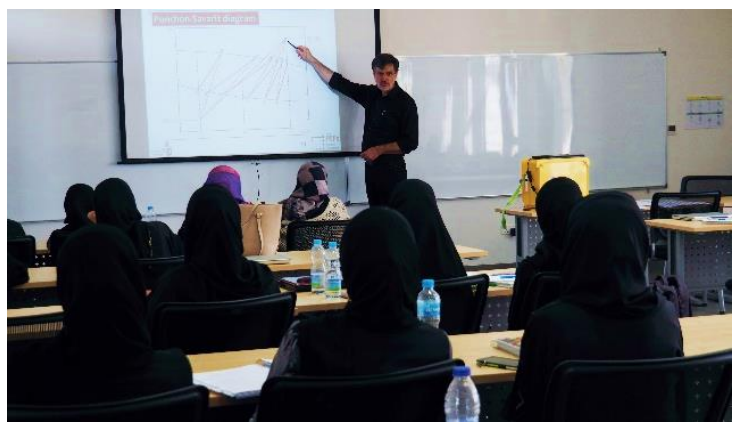

Fig. 3: Explaining the Ponchon-Savarit method in Oman

For further questions and comments, please contact:

Andreas Pfennig

phone: +32 (0) 4 366-3521

andreas.pfennig@ulg.ac.be 


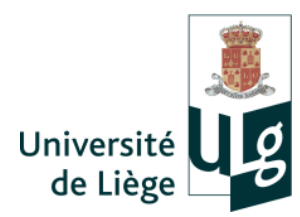

The Schnapps Project

\author{
Andreas Pfennig
}

\section{Integrated Project}

The curriculum for chemical engineers at the University of Liège includes an integrated project already in the Bachelor studies. The goal of the integrated project is to acquire and train soft skills as well as to join the knowledge obtained from different courses of the curriculum to solve a practical challenge. Since this course is included in the Bachelor studies, the level of the problem to be solved should be manageable. Thus, it appeared that the Branntwein AG, developed originally at RWTH Aachen many years ago, could be a casemodel to be adopted as schnapps project to meet all requirements to be met by the integrated project.

\section{Schnapps Project}

First, the formal requirements were checked, i.e. the administration of Liège approached for clarifying the tax requirements. After this had been favorably decided, the project could start. Since this was the first implementation of the schnapps project at the University of Liège, some additional hurdles had to be mastered, like also getting the university administration, which is responsible internally for such tax issues, to support the schnapps team. We also thankfully acknowledge financial support received from the Faculty of Applied Sciences for equipment and consumables. The schnapps team was then formed, the tasks explained, and then the sub-teams could start working.

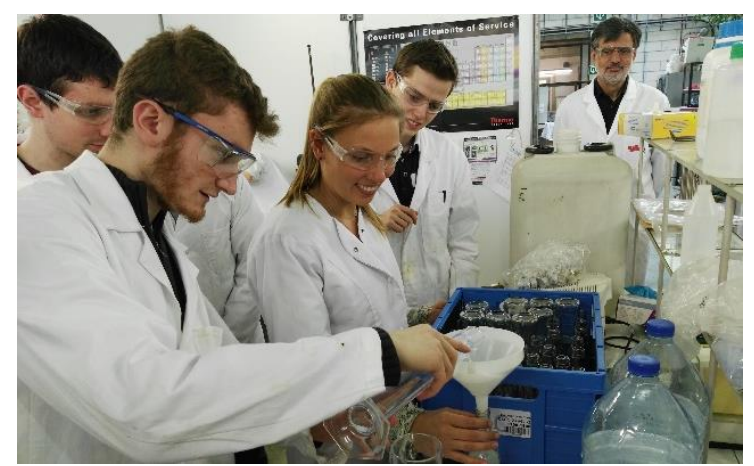

Fig. 1: Working in the schnapps lab
After having organized a schnapps project already at different universities, it is interesting to realize the very different attitude of the students to the challenges. While in Aachen the students were eagerly applying chemical engineering principles, in Graz the students of course knew how to distill schnapps from practical experience at home. Thus, it required significant effort in Graz to get the students to first properly design the process before realizing it. In Liège on the other hand, the students are quite careful in applying their knowledge and tend to be relatively cautious. This of course results from the integrated project being scheduled quite early in the curriculum. Thus in Liège the integrated project indeed supports that the students learn to gain confidence in what they learned and its application.

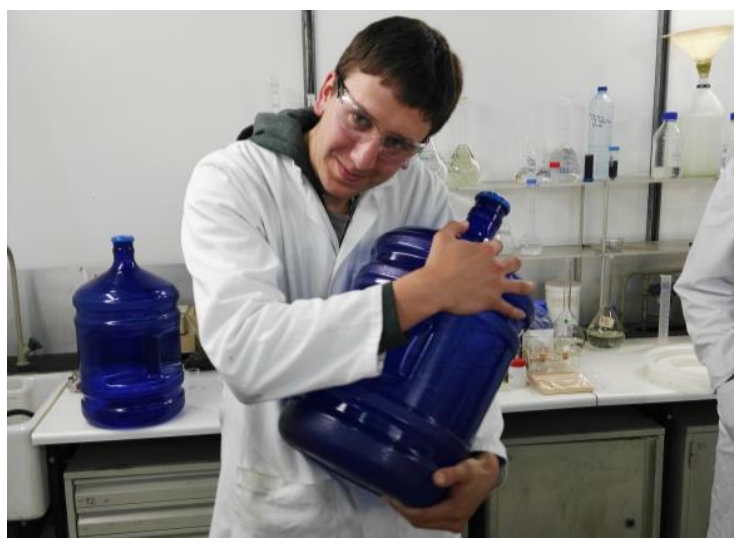

Fig. 2: The final product

The students decided to produce the schnapps from apples, properly performed the fermentation and afterwards the wine was distilled twice. Finally, the students also had to document the project. Quasi as a substitute for the project report a website has been created, which can be found at schnapsteam.wixsite.com/integrated-project

For further questions and comments, please contact:

Andreas Pfennig

phone: +32 (0) 4 366-3521

andreas.pfennig@ulg.ac.be 


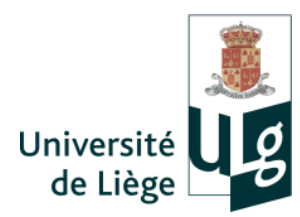

\section{Dissertations}

Anton Markus Reiter, 11.11.2016: Thermodynamische Beschreibung von fossilen und biogenen Treibstoffen.

Jan Bernd Bol, 11.11.2016: Optimale Versuchsplanung unter Berücksichtigung der Prozesskosten am Beispiel der Phytoextraktion.

Eva Kalvoda, 11.11.2016: Einfluss von Konzentrationsgradienten auf das Verhalten von Einzeltropfen in Extraktionskolonnen.

Artur Pereira Neto, 12.03.2015: Evaluation of a Molecular-Dynamic Based Method for the Direct Simulation of a Distillation Column on Atomistic Scale.

Murat Kalem, 15.12.2014: Einzeltropfenbasierte Simulation von pulsierten Siebbodenkolonnen für die Reaktivextraktion

Tobias Grömping, 15.12.2014: Auslegung von Extraktionskolonnen mit geordneten Packungen.

Dirk Delinski, 03.07.2014: Untersuchung der Phytoextraktion in einer standardisierten Laborapoparatur mittels Modellbasierter Experimenteller Analyse (MEXA).

Miguel Ángel Caraucán Dávila, 03.07.2014: Systematic Investigation of Distillation Efficiency in Aqueous Systems.

Philipp Emanuel Frenzel, 10.04.2014: Bewertung von Syntheserouten auf Basis von Exergiebilanzen.

Sebastian Ruckes, 10.04.2014: Einfluss von Mulm auf dasd Abscheideverhalten organisch-wässriger Stoffsysteme.

\section{Publications}

An updated list of publications is available at http://orbi.ulg.ac.be/ph-search?uid=U222548

Leis, D., Lauß, B., Macher-Ambrosch, R., Pfennig, A., Nidetzky, B. \& Kratzer, R. (2016) Integration of whole-cell reaction and product isolation: Highly hydrophobic solvents promote in situ substrate supply and simplify extractive product isolation. Journal of Biotechnology, accepted. 10.1016/.j.jbiotec.2016.11.021.

Kopriwa, N., \& Pfennig, A. (2016). Characterization of Coalescence in Extraction Equipment Based on Lab-Scale Experiments. Solvent Extraction \& Ion Exchange, 34(7), $\underline{622-642 .}$

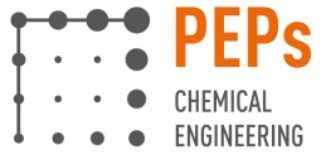

Erhardt, F., Haas, T., Roos, D., Poetter, M., Schubert, A., Pfeffer, J. C., Tacke, T., Haeger, H., Pfennig, A., \& Przybylski-Freund, M.-D. (2016). Liquid Cation Exchanger. United States: US 9,315,443 B2, United States Patent and Trademark Office.

Wallek, T., Pfleger, M., \& Pfennig, A. (2016). Discrete Modeling of Lattice Systems: The Concept of Shannon Entropy Applied to Strongly Interacting Systems. Industrial \& Engineering Chemistry Research, 55(8), 2483-2492.

Pfleger, M., Wallek, T., \& Pfennig, A. (2015). Discrete Modeling: Thermodynamics Based on Shannon Entropy and Discrete States of Molecules. Industrial and Engineering Chemistry, 54, 4643-4654.

Ayesterán, J., Kopriwa, N., Buchbender, F., Kalem, M., \& Pfennig, A. (2015). ReDrop A Simulation Tool for the Design of Extraction Columns Based on Single-Drop Experiments. Chemical Engineering and Technology, 38(10), 1894-1900.

Reiter, A. M., Wallek, T., Pfennig, A., \& Zeymer, M. (2015). Surrogate Generation and Evaluation for Diesel Fuel. Energy \& Fuels, 29, 4181-4192.

Bednarz, A., Rüngeler, B., \& Pfennig, A. (2014). Use of Cascaded Option Trees in Chemical-Engineering Process Development. Chemie Ingenieur Technik, 86(5), 611-620.

Frenzel, P., \& Pfennig, A. (2014). Bewertung der steigenden Nachfrage nach DieselKraftstoffen hinsichtlich ihrer CO2Emissionen. In U., Bachhiesl (Ed.), Innehalten und Ausblick: Effektivität und Effizienz für die Energiewende (pp. 1-9).

Frenzel, P., Hillerbrand, R., \& Pfennig, A. (2014). Exergetical Evaluation of Biobased Synthesis Pathways. Polymers, 6(2), 327345.

Frenzel, P., Hillerbrand, R., \& Pfennig, A. (2014). Increase in energy and land use by a bio-based chemical industry. Chemical Engineering Research and Design, 92, 2006-2015.

Mungma, N., Chuttrakul, P., \& Pfennig, A. (2014). Liquid-liquid Phase Separation in Batch Settling with Inclined Plate. Jurnal Teknologi - Science and Engineering, 67(4), 55-58. 
Université
de Liège

Pfleger, M., Wallek, T., \& Pfennig, A. (2014). Contraints of Compound Systems: Prerequisites for Thermodynamic Modeling Based on Shannon Entropy. Entropy, 16(6), 29903008.

Schäffner, B., Blug, M., Kruse, D., Polyakov, M., Köckritz, A., Martin, A., Rajagopalan, P., Bentrup, U., Brückner, A., Jung, S., Agar, D., Rüngeler, B., Pfennig, A., Müller, K., Arlt, W., Woldt, B., Graß, M., \& Buchholz, S. (2014). Synthesis and Application of Carbonated Fatty Acid Esters from Carbon Dioxide Inc-luding a Life Cycle Analysis. ChemSusChem, 7(4), 1133-1139.

\section{Presentations}

Pfennig, A.: Biobased Processes: Systematically Evaluating Chances and Challenges. 1st BioSC Symposium: Towards an Integrated Bioeconomy, 21.11.2016, Cologne, Germany.

Frenzel, P., \& Pfennig, A.; Methodik zur schnellen Bewertung von Syntheserouten auf Basis von Exergiebilanzen. ProcessNetJahrestagung und 32. DECHEMAJahrestagung der Biotechnologen, 13.15.9.2016, Aachen, Germany.

Pfennig, A.: Internet Platforms for Education on Sustainability. 8th Conference on Engineering Education for Sustainable Development, 4.-7.9.2016, Brugge, Belgium.

Bednarz, A., Rüngeler, B., Scherübel, P., Schmidt, M., \& Pfennig, A. (2016). Systematic Downstream Development, Optimization and Equipment Design for Biobased Products and Processes. ProcessNetJahrestagung und 32. DECHEMAJahrestagung der Biotechnologen, 13.15.9.2016, Aachen, Germany.

Kalvoda, E., Pfennig, A.: Einfluss des Konzentrationsgradienten an der Phasengrenze auf den Stofftransport von Einzeltropfen. Jahrestreffen der ProcessNet-Fachgruppen Extraktion und Grenzflächenbestimmte Systeme und Prozesse, 14.+15.03.2016, Weimar, Germany.

Leleu, D., \& Pfennig, A.: Gel Beads to Investigate Sedimentation. Jahrestreffen der ProcessNet-Fachgruppen Extraktion und Grenzflächenbestimmte Systeme und Prozesse, 14.+15.03.2016, Weimar, Germany.

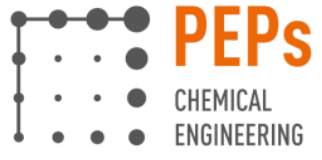

Pfennig, A., Becker, K., Bach, S., Bäcker, W., Kalem, M., Reinecke, A., \& Ruckes, S.: Challenges for Scale-Up of Batch Phase Separation. Jahrestreffen der ProcessNetFachgemeinschaft Fluiddynamik und Trenntechnik, 10.9.2015, Bamberg, Germany.

Cvetkovic, E., \& Pfennig, A.: Stofftransport an Einzeltropfen mit Konzentrationsprofil in der kontinuierlichen Phase. Jahrestreffen der ProcessNet Fachgruppen Extraktion und Mischvorgänge, 16.-17.03.2015, Heidelberg, Germany.

Pfennig, A.: Numerische Modellierung der Phasentrennung in Zentrifugalextraktoren. Jahrestreffen der ProcessNet Fachgruppen Extraktion und Mischvorgänge, 16.17.03.2015, Heidelberg, Germany.

Macher, R., Chuttrakul, P., \& Pfennig, A.: Charakterisierung und Abtrennung von Feinsttrübungen mithilfe von Zentrifugalabscheidern. ProcessNet-Jahrestagung und 31. DECHEMA-Jahrestagung der Biotechnologen, 30.9.-2.10.2014, Aachen, Germany.

Pfennig, A., \& Rüngeler, B.: Auslegung von Flüssig/Flüssig-Extraktion unter Berücksichtigung von Unsicherheiten. ProcessNet-Jahrestagung und 31. DECHEMAJahrestagung der Biotechnologen, 30.9.2.10.2014, Aachen, Germany.

Scmidt, M., Wessling, M., \& Pfennig, A.: Simulationsgestützte Auslegung von Extraktionssystemen für wässrige Zweiphasensysteme. ProcessNet-Jahrestagung und 31. DECHEMA-Jahrestagung der Biotechnologen, 30.9.-2.10.2014, Aachen, Germany.

Cvetkovic, E., \& Pfennig, A.: Kombinierte Modellierung von Sedimentation und Stofftransport für die Simulation von Extraktionskolonnen. ProcessNetJahrestagung und 31. DECHEMAJahrestagung der Biotechnologen, 30.9.2.10.2014, Aachen, Germany.

Scherübel, P., \& Pfennig, A.: A new approach to coil-planet centrifuges for extraction and phase separation in downstream processing. ISEC 2014, International Solvent Extraction Conference, 8.-11.09.2014, Würzburg, Germany. 


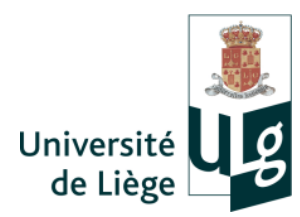

Bol, J. B., \& Pfennig, A.: Optimizing plantmaterial extraction processes. ISEC 2014, International Solvent Extraction Conference, 8.-11.09.2014, Würzburg, Germany.

Cvetkovic, E., \& Pfennig, A.: Combined sedimentation and mass-transfer experiments with a concentration gradient in the continuous phase. ISEC 2014, International Solvent Extraction Conference, 8.-11.09.2014, Würzburg, Germany.

Pfennig, A.: ReDrop for Column Simulation. Paper presented at Advanced Course, ISEC 2014, International Solvent Extraction Conference, 8.-11.09.2014, Würzburg, Germany.

Pfennig, A.: Settler Design Based on LabScale Experiments. Paper presented at Advanced Course, ISEC 2014, International Solvent Extraction Conference, 8.11.09.2014, Würzburg, Germany.

Bednarz, A., Scherübel, P., Spieß, A., \& Pfennig, A.: The use of option trees for the selection of solvents and reactive extractants for the design of biocompatible separation processes. ISEC 2014, International Solvent Extraction Conference, 8.-11.09.2014, Würzburg, Germany.

Chuttrakul, P., \& Pfennig, A.: Analyzing the sedimentation and coalescence behavior of polydisperse droplets in opaque systems using ultrasonic technique. ISEC 2014, International Solvent Extraction Conference, 8.-11.09.2014, Würzburg, Germany.

Macher, R., \& Pfennig, A.: Numerical modelling of centrifugal settlers based on experimental data. ISEC 2014, International Solvent Extraction Conference, 8.-11.09.2014, Würzburg, Germany.

Rüngeler, B., \& Pfennig, A.: Liquid-liquid extraction design under uncertainty. ISEC 2014, International Solvent Extraction Conference, 8.-11.09.2014, Würzburg, Germany.

Schmidt, M., Wessling, M., \& Pfennig, A.: Simulation based design of extraction columns for aqueous two-phase systems. ISEC 2014, International Solvent Extraction Conference, 8.-11.09.2014, Würzburg, Germany.

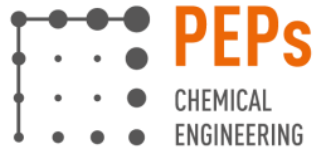

Reiter, A. M., Wallek, T., \& Pfennig, A.: Evaluation of Real Component Surrogates for Diesel Fuel. 27th European Symposium on Applied Thermodynamics - ESAT2014, 6.9.07.2014, Eindhoven, Netherlands.

Pfennig, A. (2014). Wie lange reicht Erdöl? Globale Bilanzen als ein Wegweiser in eine nachhaltige Zukunft. Lange Nacht der Forschung, 4.4.2014, Graz, Austria.

Chuttrakul, P., \& Pfennig, A.: Sedimentation and coalescence behavior of polydisperse droplets in viscous systems. Jahrestreffen der Fachgruppen Extraktion und Fluidverfahrenstechnik, 27.-28.3.2014, Fulda, Germany.

Chuttrakul, P., Tantichumnan, C., Kangsadann, T., \& Pfennig, A.: Influence of viscosity on sedimentation and coalescence in horizontal settler. Jahrestreffen der Fachgruppen Extraktion und Fluidverfahrenstechnik, 27.-28.3.2014, Fulda, Germany.

Cvetkovic, E., Bol, J. B., \& Pfennig, A.: Optimierung der Modellierung von Extraktionskolonnen anhand von verbesserten Einzeltropfenversuchen. Jahrestreffen der Fachgruppen Extraktion und Fluidverfahrenstechnik, 27.-28.3.2014, Fulda, Germany.

Leeheng, K., Cvetkovic, E., Kangsadan, T., \& Pfennig, A.: Simultaneous measurement of sedimentation and mass transfer of single drops. Jahrestreffen der Fachgruppen Extraktion und Fluidverfahrenstechnik, 27.28.3.2014, Fulda, Germany.

Pungsang, P., Chuttrakul, P., Scherübel, P., Kangsadan, T., \& Pfennig, A.: Modeling of coalescence behavior in highviscosity systems. Jahrestreffen der Fachgruppen Extraktion und Fluidverfahrenstechnik, 27.28.3.2014, Fulda, Germany.

Reiter, A. M., Wallek, T., \& Pfennig, A.: Validierung des Realkomponentenansatzes für Diesel anhand realer Surrogate. 40. Tieftemperatur-Thermodynamik-Kolloquim 9.-12.2.2014, Schladming, Austria.

Schmid, M., Wallek, T., \& Pfennig, A.: Nutzungsoptimierte Modellierungstiefe von Anlagensimulationen. 40. TieftemperaturThermodynamik-Kolloquim 9.-12.2.2014, Schladming, Austria. 